Article

\title{
Banana Biomass Estimation and Yield Forecasting from Non-Destructive Measurements for Two Contrasting Cultivars and Water Regimes
}

\author{
Bert Stevens ${ }^{1, * \mathbb{C}}$, Jan Diels ${ }^{2}{ }^{\circ}$, Allan Brown ${ }^{3}$, Stanley Bayo ${ }^{3}$, Patrick A. Ndakidemi ${ }^{4}$ \\ and Rony Swennen $1,3,5$ (D) \\ 1 Department of Biosystems, KU Leuven, Willem De Croylaan 42-Box 2455, 3001 Heverlee, Belgium; \\ R.Swennen@cgiar.org \\ 2 Division of Soil and Water Management, KU Leuven, Celestijnenlaan 200e-Box 2411, 3001 Leuven, Belgium; \\ Jan.diels@kuleuven.be \\ 3 International Institute of Tropical Agriculture, IITA, Arusha P.O. Box 447, Tanzania; \\ A.brown@cgiar.org (A.B.); bayostanleyqamara@gmail.com (S.B.) \\ 4 Nelson Mandela African Institution of Science and Technology, NMAIST, Arusha P.O. Box 447, Tanzania; \\ patrick.ndakidemi@nm-aist.ac.tz \\ 5 Bioversity International, Willem De Croylaan 42, 3001 Heverlee, Belgium \\ * Correspondence: Bert.stevens@kuleuven.be or bert.stvns@gmail.com
}

Received: 13 July 2020; Accepted: 18 September 2020; Published: 21 September 2020

\begin{abstract}
The largest abiotic constraint threatening banana (Musa spp.) production is water stress, impacting biomass buildup and yields; however, so far no studies have investigated the effects of water stress on allometric equations in banana. Weighted least square regression models were built for (i) estimating aboveground vegetative dry biomass (ABGVD) and corm dry biomass (cormD) and (ii) forecasting bunch fresh weight (bunchF), based on non-destructive parameters for two cultivars, Mchare Huti-Green Bell (HG, AA) and Cavendish Grande Naine (GN, AAA), under two irrigation regimes: full irrigation (FI) and rainfed (RF). FI affected growth, yield, and phenological parameters in the field $(p<0.05)$ depending on the onset of moisture stress. Pseudostem volume $\left(\mathrm{V}_{\text {pseudo }}\right)$ proved a good predictor for estimating ABGVD $\left(\mathrm{R}^{2}\right.$ adj $=0.88-0.92$; RRMSE $\left.=0.14-0.19\right)$, but suboptimal for cormD $\left(R^{2}\right.$ adj $=0.90-0.89$, RRMSE $=0.21-0.26$ for HG; $R^{2}$ adj $=0.34-0.57$, RRMSE $=0.38-0.43$ for $\mathrm{GN})$. Differences between RF and FI models $(p<0.05)$ were small as $95 \% \mathrm{CI}$ overlapped. $\mathrm{V}_{\text {pseudo }}$ at flowering predicted bunchF in FI plots correctly $\left(R^{2}{ }_{\text {adj }}=0.70\right.$ for $H G, R^{2}$ adj $=0.43$ for GN; RRMSE $=0.12-0.15$ for HG and GN). Differences between FI and RF models were pronounced as $95 \% \mathrm{CI}$ did not overlap $(p<0.05)$. Bunch allometry was affected by irrigation, proving bunchF forecasting needs to include information on moisture stress during bunch filling or information on bunch parameters. Our allometric relationships can be used for rapid and non-destructive aboveground vegetative biomass (ABGVD) assessment over time and to forecast bunch potentials based on $\mathrm{V}_{\text {pseudo }}$ at flowering.
\end{abstract}

Keywords: allometry; biomass; bunch; Cavendish; forecasting; regression; Musa spp.; moisture stress; East African Highland Banana

\section{Introduction}

Banana (Musa spp.), the most important fruit worldwide [1], is a long cycle crop with a vegetative phase between 7-13 months depending on environmental conditions, such as water and nutrients [2]. For most of the plant's life, it develops without a bunch. Bunch biomass is linked to biomass buildup during the vegetative phase (aboveground: pseudostem, petioles and leaves, 
and belowground: corm) [3], as assimilates are translocated from within the banana mat to the bunch after bunch emergence $[2,4,5]$. Monitoring vegetative biomass enables the following of growth over time and, due to its link with yields, can provide an indicator of future yields.

Monitoring biomass over time can be done by destructive whole-plant sampling, but it is more practical to quantify the biomass during the growth cycle or to forecast the yield from non-destructive observations using allometric relationships. Destructive sampling is very labor intensive, time consuming, and provides only one sampling point for one plant. To capture biomass over time, plants need to be sampled periodically, requiring lots of plants and space. Sampling plants before they are harvest ready also stands in the way of quantifying bunch weights.

Allometric relationships specify how growth and size in plants or plant components is related to their allocated biomass [6,7]. Parameters can be vegetative characteristics (e.g., pseudostem girth at base) [3,5,8-11], bunch components (e.g., number of hands, fingers, finger volume) $[12,13]$ or phenological observations (e.g., days to flowering, days to harvest). Vegetative parameters that are well connected to biomass, and/or parameters that are connected to future yields and allow bunch weight 'forecasting', are of significant interest. Measuring such parameters in the field is much faster than destructive sampling, and leaves fields intact. Allometric equations are useful for periodic biomass monitoring in the field [9] which is needed to calibrate and further improve computer crop simulation models $[5,14,15]$. Crop models can be used (among others) to analyze management interventions under different environments, to mitigate and adapt crop production to climate change $[12,16,17]$ and for economic analysis to manage financial decisions (e.g., manpower and cost of agricultural inputs as irrigation) [15]. As allometric relationships are the foundation of such models, correct relationships are of crucial importance.

Allometric relationships were previously developed for a limited number of banana cultivars for both vegetative and bunch biomass estimation. Nyombi et al. [5] developed allometric relationships for both biomass and bunch weight estimation for two East African highland banana (EAHB) cultivars (Mbwazirume and Kisansa) with data from two locations under various nutrient regimes. Their models followed a power function using girth and height of pseudostem as predictors, whereby covariates included banana phenological stages (vegetative, flowering, and harvest). Plants were irrigated, but with unspecified amounts of water, and fresh bunch weights ranged from 20-40 kg plant ${ }^{-1}$, indicating stressed conditions. Pooling data across cultivars and growth stages lead to a high $\mathrm{R}^{2}$ (>0.7) but increased the variance in biomass estimations. Model performance increased when data were partitioned between growth stages, indicating that allometric relationships vary with the growth stage. Yamaguchi and Araki [10] estimated biomass components using linear regression models based on pseudostem volume $\left(\mathrm{V}_{\text {pseudo }}\right)$ for EAHB cultivars from farmers' fields. Models had good fits $\left(R^{2}=0.93\right)$ but the plant sample was small $(n=14)$ and stress could not be excluded as plants were rainfed. Negash et al. [8] estimated biomass based on pseudostem diameter and height in Enset (Ensete ventricosum), another genus of the Musaceae. Models performed well for total biomass estimation $\left(\mathrm{R}^{2}>0.89\right)$, but plants came from rainfed farmers' fields without information on potential stresses.

Allometric models for bunch weight estimation were previously created, but these include parameters that change until harvest so cannot be used in forecasting bunch weights. Soares et al. [12] estimated bunch weights using multiple linear regression and neural networks for an AAAB tetraploid hybrid. Models were accurate $\left(R^{2}>0.71\right)$, but predictors included variables that can only be measured in a destructive manner at harvest (e.g., average fruit weight at harvest). Woomer et al. [13] estimated bunch weights for a rainfed EAHB cv. Mbwazirume based on estimated bunch volume through linear regression $\left(R^{2}=0.85-0.94\right)$, but as bunch volume changes until harvest [2], yields were not forecasted and no information on potential stress was given. Wairegi et al. [9] quantified bunch weights of 39 triploid EAHB cultivars from 179 farms in Uganda, whereby multiple linear regression models used pseudostem girth at base and height at $1 \mathrm{~m}$, number of hands, and number of fingers in the lower row of the second hand as predictors. Data partitioning along cultivars, developmental stages, and regions improved model accuracy but differences were not significantly different compared to the pooled 
dataset. Plants were rainfed and given the wide range of bunch weights in this study (2-60 kg plant $\left.{ }^{-1}\right)$ stress from multiple sources was presumed, but its effect on allometry was not analyzed.

The major constraint in all previously developed allometric models is that fields were not growing under optimal conditions as they were stressed by inadequate amounts of water and/or nutrients. Water (excess and deficit) is the most limiting abiotic constraint to banana production [18]. Suboptimal rainfall may lead to significant reduction in vegetative parameters (e.g., pseudostem height, girth), bunch components (number of hands, number of fingers, individual finger weight, fruit filling) [19], and may delay phenological events as flowering or harvest [20,21]. Parameters underlying allometric models are often impacted by moisture, but the overall effect on the relationship between a parameter and allocated biomass due to soil moisture is not specified in earlier allometric models. Their general use and applicability can be questioned. Similar genotypes may lead to different biomass allocation patterns and phenotypes under different biotic and abiotic environments [22], and banana has shown dry matter allocation plasticity due to drought and soil nutrients [23] and plant density [24]. Furthermore, due to the large phenotypic and or genetic differences between banana cultivars, allometric models can differ between cultivars $[5,9]$.

So far, no research has compared allometric models between differently irrigated plants in the same field. As allometric models relate growth and size, which are affected by soil moisture, to accumulated biomass, we are interested to check whether allometric relationships remain similar under different soil moisture regimes.

The objective of this research was three-fold:

Firstly, to assess the effect of soil moisture on growth parameters, phenology and growth rates using two distinctly different cultivars: the EAHB cv. Mchare-Huti Green Bell (AA), a diploid, and the Cavendish-Grande Naine (AAA), a triploid of immense commercial appeal.

Secondly, to use easily observable plant growth parameters to establish allometric relationships in both cultivars for (i) vegetative biomass estimation (aboveground: pseudostem, petioles, and leaves and belowground: corm) to allow monitoring vegetative biomass production over time, and (ii) bunch weight forecasting to allow quantifying bunch weights before harvest.

Thirdly, to compare these allometric relationships across water regimes for both cultivars to assess whether banana plasticity under drought results in significant different relationships. As drought readily affects vegetative parameters, yield, and phenology $[2,18,22]$, we hypothesize drought to significantly influence allometric relationships of both vegetative biomass estimation and bunch weight forecasting.

\section{Materials and Methods}

\subsection{Experimental Design}

Experiments were established in fields of the International Institute of Tropical Agriculture (IITA) and the Nelson Mandela African Institution of Science and Technology (NM-AIST) in Arusha, Tanzania $\left(3^{\circ} 23^{\prime} 58^{\prime \prime} \mathrm{S}, 36^{\circ} 47^{\prime} 48^{\prime \prime} \mathrm{E}\right)$ at an altitude of $1188 \mathrm{~m}$ asl as described in detail in Stevens et al. [25]. Soils are Endocalcic Phaeozems (Geoabruptic, Clayic, Humic) [26], moderately shallow to deep $(90-120 \mathrm{~cm})$ with a silty clay loam to silty clay texture. The climate is a tropical highland climate with a moderately cool thermal zone. Rainfall follows a bimodal yearly pattern with a long rainy season extending from late March to early June and a shorter rainy season from October to December, although rainfall is variable from year to year $[25,27]$.

Total precipitation received during the experiment was about $903 \mathrm{~mm}$ year $^{-1}$ for $\mathrm{HG}$, and $913 \mathrm{~mm}_{\text {year }}{ }^{-1}$ for GN, lower than those for optimal banana production (1100-2650 $\mathrm{mm} \mathrm{year}^{-1}$ ) and not evenly spread (dry spells of more than two months) (Figure 1a) implying the need for irrigation [19,28,29]. 


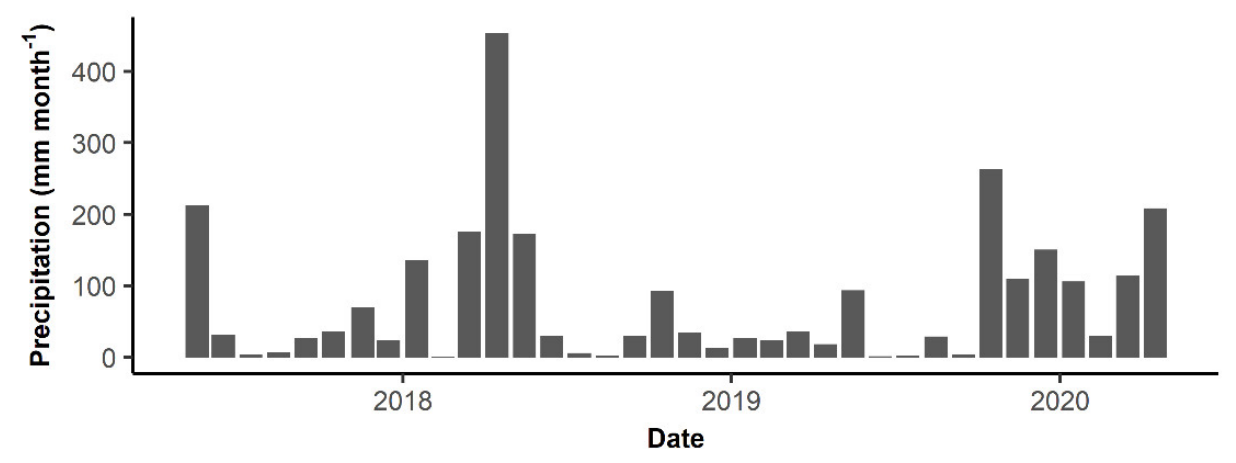

(a)

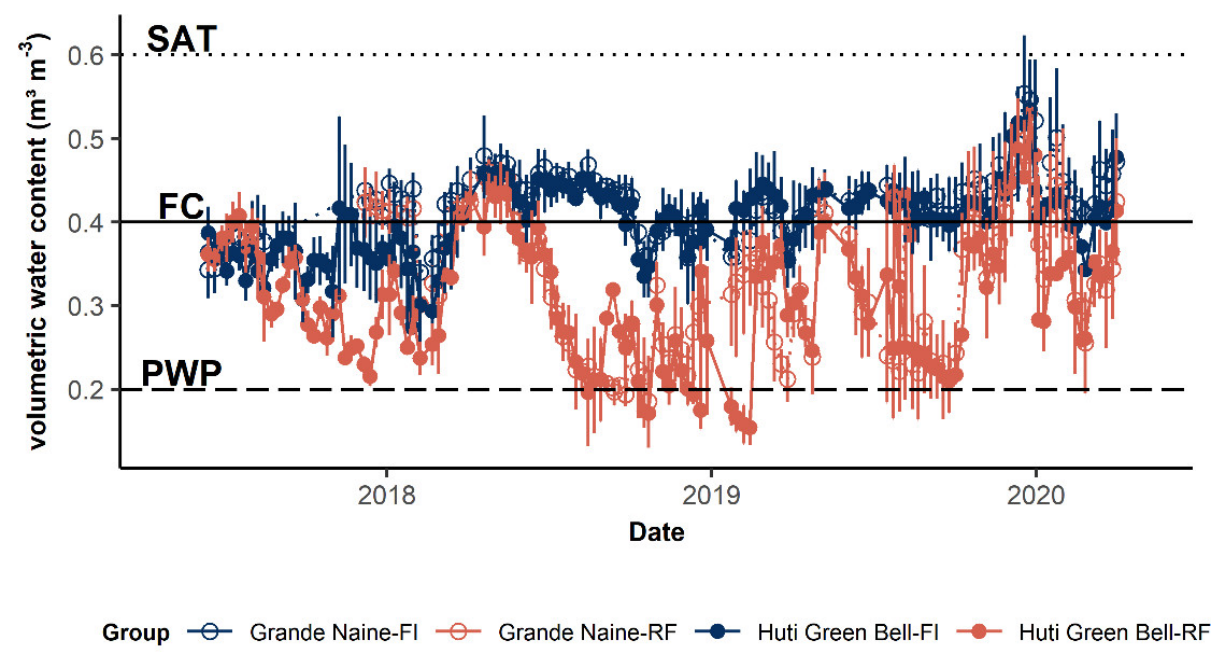

(b)
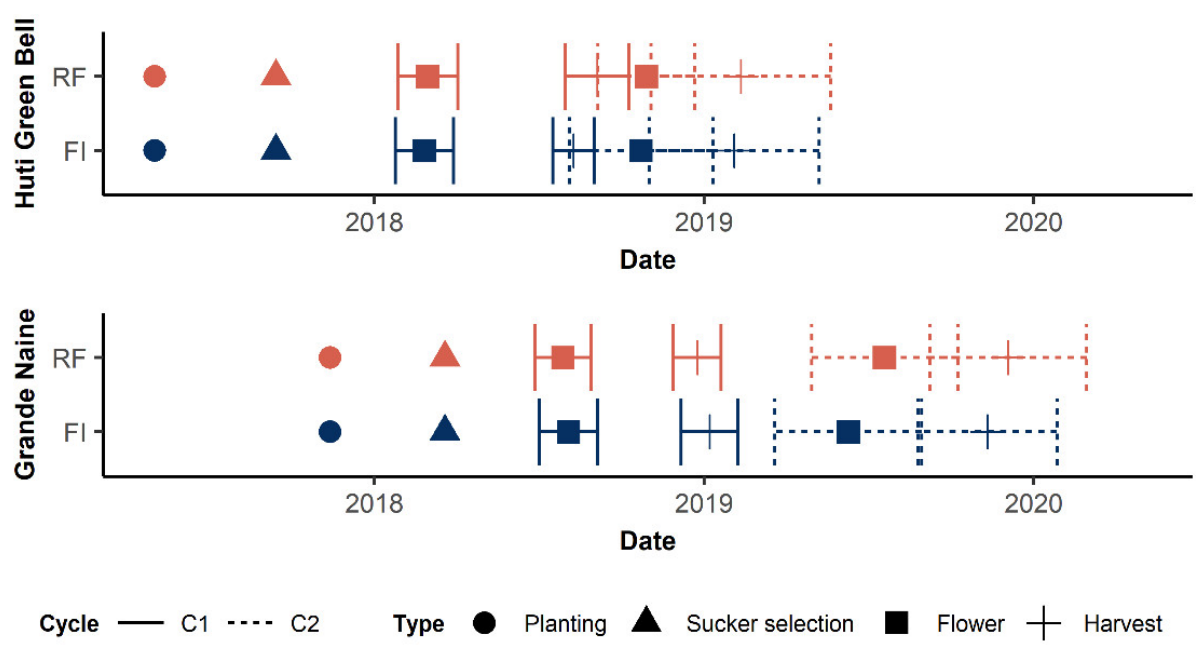

(c)

Figure 1. Water regimes in Huti Green and Grande Naine Experiments. (a) Precipitation $\left(\mathrm{mm}\right.$ month $\left.^{-1}\right)$ in Arusha, Tanzania over the course of the experiments; (b) Average weekly volumetric water content, vwc $\left(\mathrm{m}^{3} \mathrm{~m}^{-3}\right)$ in the upper $60 \mathrm{~cm}$ of the soil under two irrigation regimes (FI: full irrigation noted in blue, and RF: rainfed noted in orange). Error bars note mean \pm standard deviation. SAT notes the vwc at saturation, FC notes the vwc at field capacity and PWP notes the vwc at permanent wilting point; (c) Phenological events for Huti Green Bell and Grande Naine (planting, sucker selection, flowering and harvest) for cycle 1 (C1) and cycle 2 (C2). Error bars note mean date \pm standard deviation. Planting and sucker selection occurred on a single day, hence no standard deviations are present. 
Two experiments were carried out differing in cultivar and date of planting over the course of two full crop cycles (until harvest of C2). Planting material was provided by IITA, Arusha, Tanzania and Crop Bioscience Solutions Ltd, Arusha, Tanzania. In experiment 1, the EAHB Huti Green Bell (HG, Musa AA Mchare subgroup) was planted on 3 May 2017. In experiment 2, Grande Naine (GN, Musa AAA Cavendish subgroup) was planted on 17 November 2017. The diploid HG is characterized by a slender tall pseudostem, with erect foliage and a bunch that bears fruits with marked ridges [30]. The triploid GN is characterized by a short, thick pseudostem, with semi-drooping foliage and producing almost round fingers [31]. Both cultivars are of significantly different phenotypical constitution. Planting material for both experiments consisted of in vitro plants, hardened in growth chambers and screen houses. Plant spacing was $2 \mathrm{~m}$ (row) $\times 3 \mathrm{~m}$ (line) leading to 1666 plants ha $^{-1}$.

The design was a blocked design with drip irrigation as treatment but given the infrastructure the irrigation treatments could not be randomized (Figure S1). In experiment 1, two blocks were planted with HG. Each block contained five rows of 15 mats, subdivided in three plots of 25 mats $(5 \times 5)$, of which the central nine mats $(3 \times 3)$ were used for continuous data collection. Each block consisted of a different irrigation treatment. For HG, there were three plots for each treatment. Border mats were used for periodic destructive sampling. In experiment 2 , four blocks were planted with GN. Each block contained five rows of 14 mats, subdivided in two plots of 35 mats $(7 \times 5)$, receiving two different irrigation treatments. The central nine mats $(3 \times 3)$ in each plot were used for continuous growth data collection, leading to four replications (plots) per treatment. The first and last two mats of each row $(2 \times 5$ mats $)$ together with the border rows were used for periodic destructive sampling. Each treatment was replicated four times across the blocks.

All mats received irrigation for the first four months post-transplant (establishment period, four MAP). Thereafter, two irrigation treatments were applied: optimal 'full' irrigation (FI) and rainfed (RF), based on volumetric water contents in the root zone (as determined by Time Domain Reflectometry) (Figure $1 b$ ). In the FI treatment, mats received water whenever more than $25 \%$ of total available water in the root zone was depleted. No supplemental irrigation was provided in RF treatments after the initial four month establishment period, leading to divergence of soil moisture between RF and FI in HG and GN closely following the dry seasons (Figure 1a,b). In HG, soil moisture first became significantly different at 23 weeks after planting (WAP) (October 2017) until 45 WAP (March 2018) during the vegetative stage of $C 1$, followed by a rainy season after which they diverged again from 55 WAP (May 2018). In GN, RF plots became significantly more depleted from 27 WAP onwards (May 2018), close to the onset of flower emergence of C1 [25], therefore in GN most of the vegetative growth of $\mathrm{C} 1$ occurred under similar soil moisture in RF and FI plots.

Irrigation and precipitation combined, FI plots received approx. $3100 \mathrm{~mm}(\mathrm{HG})$ and $4003 \mathrm{~mm}$ (GN) over the entire growing season (until harvest of C2), compared to RF plots which received $1916 \mathrm{~mm}$ (HG) and $2549 \mathrm{~mm}$ (GN). FI plots received approx. $1522 \mathrm{~mm} \mathrm{year}^{-1}$ (HG) and $2000 \mathrm{~mm}$ year $^{-1}$ (GN). RF plots received approx. $935 \mathrm{~mm} \mathrm{year}^{-1}$ (HG) and $1297 \mathrm{~mm} \mathrm{year}^{-1}(\mathrm{GN})$. For a more detailed explanation on the onset of moisture stress and its effect on leaf formation and canopy cover in these fields, the reader is referred to Stevens et al. [25].

Mats received an optimal mixture of mineral fertilizers and manure, to exclude nutrient stresses [32]. Mineral fertilizers were split applied: $153 \mathrm{~kg} \mathrm{~N} \mathrm{ha}^{-1}$ year $^{-1}$ (urea), $206 \mathrm{~kg} \mathrm{~K} \mathrm{ha}^{-1}$ year ${ }^{-1}$ (Muriate of potash), $19.26 \mathrm{~kg} \mathrm{Mg} \mathrm{ha}^{-1}$ year ${ }^{-1}$, and $25.6 \mathrm{~kg} \mathrm{~S} \mathrm{ha}^{-1}$ year $^{-1}\left(\mathrm{MgSO}_{4}\right)$ were applied monthly in the rainy season and every two months in the dry season, while $40.2 \mathrm{~kg} \mathrm{P} \mathrm{ha}^{-1} \mathrm{year}^{-1}$ (triple super phosphate) was applied every five months. Twenty $\mathrm{L}$ of fresh farmyard cow manure was applied per mat twice yearly before the start of the rainy season.

All suckers were allowed to grow until four MAP after which suckers were selected for C2 (Figure S2). Afterwards, suckers were pruned on a monthly basis until bunch filling of C1, when a sucker for C3 was chosen. Maximally, three generations were allowed to grow at any time. Weeds and dead leaves were cut monthly and removed from the field. No pests were present in the field. 
No disease control was applied, except for Black Sigatoka (Pseudocercospora fijiensis) in the wet season, when moderately infected leaves were pruned to avoid further spread of this fungus [25].

\subsection{Plant Data Collection}

Growth data included periodic non-destructive growth data and destructive data (Table 1).

Table 1. Growth data measured. Non-destructive data includes phenological data collected for the individual plants on a mat, vegetative growth data measured monthly at the plot level on all plants on a mat and at harvest/destructive sampling of a plant, and bunch data measured on harvest ready plants. Destructive data includes biomass data that was determined destructively at harvest or during periodic destructive sampling.

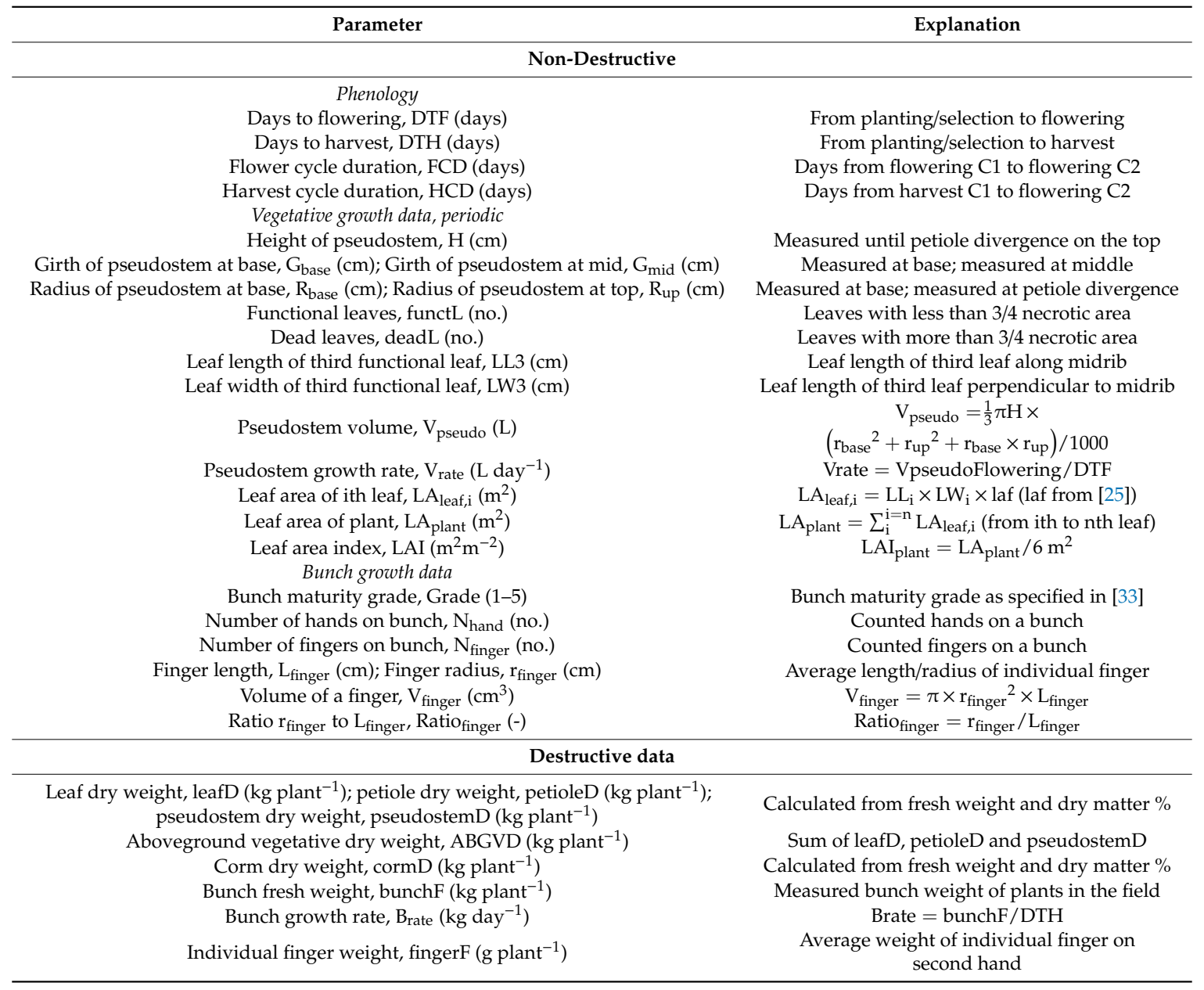

Non-destructive growth data were measured monthly at the plot level $(3 \times 3$ mats), on all individual plant cycles (cycle 1, C1; cycle 2, C2 and cycle 3, C3) present on the mat until harvest of C2 (Table 1). The main plant is the oldest plant on a mat, whereby ratoon plants (sucker) are new selected shoots springing from the base of the plant. To address multicollinearity, measured parameters were recombined into new parameters as pseudostem volume $\left(\mathrm{V}_{\text {pseudo }}\right)$, leaf area index (LAI), $\mathrm{V}_{\text {finger }}$, and Ratio finger (Table 1).

Leaf areas were estimated by measuring leaf length, leaf width, and using an experimentally determined leaf area factor (laf) as explained by Stevens et al. [30]. LAI was determined by summing the area of all the leaves on a banana plant and dividing it by the ground area for each mat.

Phenological events as days to flowering (DTF) and days to harvest (DTH) were noted for each plant on a mat. As C3 has not fully flowered and harvested, phenological events were only presented for $\mathrm{C} 1$ and $\mathrm{C} 2$ (Table 2). For C1, the DTF and DTH were determined from planting. For C2, the DTF and 
DTH were determined from the moment of sucker selection until flowering and harvest. Flower cycle duration (FCD) notes the duration in days between flower emergence of $\mathrm{C} 1$ and $\mathrm{C} 2$ (successive cycles) on the same mat, and harvest cycle duration (HCD) notes the duration in days between successive harvest of $\mathrm{C} 1$ and $\mathrm{C} 2$ on the same mat.

The pseudostem volume at flower emergence $\left(\mathrm{V}_{\text {pseudo, Flower }}\right)$ and the LAI at flower emergence ( $\mathrm{LAI}_{\text {Flower }}$ ) were interpolated for flowering dates through local non-parametric regression (loess) on the $\mathrm{V}_{\text {pseudo }}$ and LAI data collected over the growing season (Figure S3). Similarly, the $\mathrm{V}_{\text {pseudo }}$ and LAI of the follower ( $\mathrm{S}$ for sucker) of the flowering main plant was determined ( $\mathrm{V}_{\text {pseudo, FlowerS }}$ and LAI $\mathrm{Ilower}_{\mathrm{S}}$ ).

Biomass component weights (pseudostem, leaf, petiole, bunch, and corm) were measured destructively during 'harvest' and 'periodic destructive sampling'.

At 'harvest', harvest-ready plants of $\mathrm{C} 1$ and $\mathrm{C} 2$ showing ripe bunches were cut down at the base of the pseudostem, but succeeding cycles were left on the mat. Non-destructive vegetative and bunch characteristics (Table 1) were determined on the harvested plant together with destructive biomass. Fresh weight of vegetative components (pseudostem, leaf, petioles) and bunch (bunchF) was measured using a field balance $( \pm 0.05 \mathrm{~kg})$, and subsamples were taken, chopped and dried at $80^{\circ} \mathrm{C}$ for $48 \mathrm{~h}$ in a hot-air oven (to not destroy plant tissue) until subsample weights did not vary anymore to determine the dry matter percentage (Table S1). Aboveground vegetative dry matter (ABGVD) included the pseudostem, petioles, and leaves. Hereafter, when using the term 'harvest', plants that are harvest ready for their bunches were noted.

At 'periodic destructive sampling', entire mats were randomly sampled every three months from planting onwards to obtain a database of plants spanning different sizes and growth stages including $\mathrm{C} 1, \mathrm{C} 2$, and C3 plants. From planting onwards, every three months, mats $(n=3)$ were randomly chosen from border rows or from destructive sampling areas in each treatment in both experiments. Whole mats were excavated and for each individual cycle, growth data were measured (Table 1) and biomass components (corm, pseudostem, petioles, leaves, bunch) were separated and weighted. Non-differentiated suckers (not protruding above ground level) were counted as part of the corm. All cycles present on a mat (C1, C2, and C3) were used for data collection. ABGVD was calculated similarly as at harvest. Corms were separated per cycle, weighted and corm dry matter (cormD) was calculated based on fresh corm weight and subsample dry matter percentages (Table S1).

\subsection{Moisture Effect on Plant Growth}

Kruskall-Wallis non-parametric tests $(\alpha=0.05)$ for multiple comparison of growth parameters between irrigation treatments, cultivar, and growth cycle were applied on collected growth data at flowering and harvest of $\mathrm{C} 1$ and $\mathrm{C} 2$ (Table 2).

As the effect of added water (precipitation and irrigation) is very dependent on the environment in which a plant develops the ratio (R) of cumulative water added (W) and cumulative ET0 was determined for each plant between: planting and flowering $\left(R_{P F}\right)$, flowering and harvest $\left(R_{F H}\right)$, and planting and harvest $\left(\mathrm{R}_{\mathrm{PH}}\right)$ (Table 2). 
Table 2. Descriptive plant growth parameters at flowering or harvest for plant growth cycles (Cycle 1, C1 and Cycle 2, C2) and irrigation treatments (full irrigation, FI and rainfed, RF) noted as mean ( \pm standard deviation) of cultivars Huti Green Bell (HG) and Grande Naine (GN)

\begin{tabular}{|c|c|c|c|c|c|c|c|c|}
\hline & \multicolumn{4}{|c|}{ Huti Green Bell } & \multicolumn{4}{|c|}{ Grande Naine } \\
\hline & \multicolumn{2}{|c|}{$\mathrm{C} 1$} & \multicolumn{2}{|c|}{$\mathrm{C} 2$} & \multicolumn{2}{|c|}{ C1 } & \multicolumn{2}{|c|}{$\mathrm{C} 2$} \\
\hline & FI & RF & FI & RF & FI & RF & FI & RF \\
\hline & \multicolumn{8}{|c|}{ Moisture and $E T_{0}$ Ratios } \\
\hline $\mathrm{R}_{\mathrm{PF}}(-)$ & $0.743( \pm 0.0343)^{\mathrm{TC}}$ & $0.638( \pm 0.0404)^{\mathrm{TC}}$ & $1.29( \pm 0.0408)^{\mathrm{TC}}$ & $0.807( \pm 0.0791)^{\mathrm{TC}}$ & $1.44( \pm 0.0213) \mathrm{TC}$ & $1.26( \pm 0.0448)^{\mathrm{TC}}$ & $1.33( \pm 0.0334))^{\mathrm{TC}}$ & $0.687( \pm 0.0373) \mathrm{TC}$ \\
\hline $\mathrm{R}_{\mathrm{FH}}(-)$ & $2.17( \pm 0.210)^{\mathrm{TC}}$ & $1.47( \pm 0.182){ }^{\mathrm{TC}}$ & $0.920( \pm 0.107))^{\mathrm{TC}}$ & $0.333( \pm 0.194) \mathrm{TC}$ & $1.08( \pm 0.106)^{\mathrm{TC}}$ & $0.329( \pm 0.0239)^{\mathrm{TC}}$ & $1.54( \pm 0.154)^{\mathrm{TC}}$ & $0.950( \pm 0.222)^{\mathrm{TC}}$ \\
\hline \multirow{2}{*}{$\mathrm{R}_{\mathrm{PH}}(-)$} & $1.19( \pm 0.0172)^{\mathrm{T}}$ & $0.902( \pm 0.0372) \mathrm{TC}$ & $1.17( \pm 0.0396)^{\mathrm{T}}$ & $0.661( \pm 0.0436)^{\mathrm{TC}}$ & $1.30( \pm 0.0404)$ TC & $0.873( \pm 0.0323)^{\mathrm{TC}}$ & $1.38( \pm 0.0211)^{\mathrm{TC}}$ & $0.742( \pm 0.0247){ }^{\mathrm{TC}}$ \\
\hline & \multicolumn{8}{|c|}{ Growth Data } \\
\hline Height $^{\dagger}(\mathrm{cm})$ & $304.5( \pm 18.1)^{\mathrm{TC}}$ & $272.6( \pm 14.4) \mathrm{TC}$ & $476.3( \pm 22.6)^{\mathrm{TC}}$ & $451.4( \pm 22.5) \mathrm{TC}$ & $264.1( \pm 12.1)^{\mathrm{C}}$ & $265.1( \pm 18.0)^{\mathrm{C}}$ & $277.6( \pm 19.1) \mathrm{TC}$ & $234.2( \pm 20.3) \mathrm{TC}$ \\
\hline $\mathrm{G}_{\text {base }}+(\mathrm{cm})$ & $77.3( \pm 3.57) \mathrm{TC}$ & $66.7( \pm 3.46)$ TC & $100.9( \pm 5.05) \mathrm{TC}$ & $97.0( \pm 6.09)$ TC & $91.7( \pm 4.43)^{\mathrm{C}}$ & $93.2( \pm 6.07)^{\mathrm{C}}$ & $82.3( \pm 5.36)$ TC & $72.5( \pm 5.06)$ TC \\
\hline Height $\ddagger(\mathrm{cm})$ & $305.3( \pm 20.8)^{\mathrm{TC}}$ & $272.0( \pm 23.3) \mathrm{TC}$ & $457.5( \pm 39.1)$ TC & $424.2( \pm 32.7) \mathrm{TC}$ & $258.5( \pm 18.2)^{\mathrm{C}}$ & $255.4( \pm 17.2) \mathrm{C}$ & $277.6( \pm 28.7)$ TC & $236.7( \pm 37.3) \mathrm{TC}$ \\
\hline $\mathrm{G}_{\text {base }} \ddagger(\mathrm{cm})$ & $68.0( \pm 5.42)^{\mathrm{TC}}$ & $55.7( \pm 5.56)^{\mathrm{TC}}$ & $87.0( \pm 11.6)^{\mathrm{TC}}$ & $75.2( \pm 12.9)^{\mathrm{TC}}$ & $82.0( \pm 7.25)^{\mathrm{C}}$ & $78.4( \pm 8.21)^{\mathrm{C}}$ & $82.5( \pm 7.42)^{\mathrm{TC}}$ & $72.4( \pm 7.16)^{\mathrm{TC}}$ \\
\hline $\operatorname{ABGVD} \ddagger\left(\mathrm{kg} \mathrm{plant}^{-1}\right)$ & $3.49( \pm 0.374)^{\mathrm{TC}}$ & $2.41( \pm 0.46)^{\mathrm{TC}}$ & $7.49( \pm 1.43)^{\mathrm{TC}}$ & $5.18( \pm 0.897) \mathrm{TC}$ & $4.65( \pm 0.884)^{\mathrm{TC}}$ & $4.04( \pm 0.845)^{\mathrm{T}}$ & $6.16( \pm 1.78)^{\mathrm{TC}}$ & $3.73( \pm 1.22)^{\mathrm{T}}$ \\
\hline BunchF $\ddagger\left(\right.$ kg plant $\left.^{-1}\right)$ & $25.4( \pm 3.87)^{\mathrm{TC}}$ & $19.6( \pm 3.96)^{\mathrm{T}}$ & $40.8( \pm 8.02) \mathrm{TC}$ & $24.4( \pm 0.636)^{\mathrm{T}}$ & $49.6( \pm 7.61)^{\mathrm{T}}$ & $33.2( \pm 9.1)^{\mathrm{T}}$ & $52.4( \pm 15.2)^{\mathrm{T}}$ & $33.3( \pm 9.9)^{\mathrm{T}}$ \\
\hline $\mathrm{N}_{\text {hand }} \neq$ (no.) & $9.69( \pm 0.535) \mathrm{TC}$ & $8.94( \pm 0.583)^{\mathrm{TC}}$ & $11( \pm 1.49)^{\mathrm{C}}$ & $10.8( \pm 2.5)^{\mathrm{C}}$ & $10.8( \pm 1.01)$ & $10.5( \pm 0.987)$ & $11( \pm 1.56)^{\mathrm{T}}$ & $10.2( \pm 1.67)^{\mathrm{T}}$ \\
\hline $\mathrm{N}_{\text {finger }} \neq($ no. $)$ & $151( \pm 12.0)$ TC & $128( \pm 13.7)^{\mathrm{TC}}$ & $195( \pm 50.1)^{\mathrm{TC}}$ & $163( \pm 42.3)^{\mathrm{TC}}$ & $202( \pm 21.5)$ & $202( \pm 18.3)^{\mathrm{C}}$ & $204( \pm 57.7)^{\mathrm{T}}$ & $174( \pm 43.3)$ TC \\
\hline fingerF ${ }^{(}\left(\mathrm{g} \mathrm{finger}^{-1}\right)$ & $180( \pm 27.7)^{\mathrm{TC}}$ & $160( \pm 30.7)^{\mathrm{T}}$ & $227( \pm 41.3)^{\mathrm{TC}}$ & $139( \pm 50.5)^{\mathrm{T}}$ & $253( \pm 3.53)^{\mathrm{TC}}$ & $166( \pm 4.75) \mathrm{TC}$ & $222( \pm 5.84)^{\mathrm{TC}}$ & $149( \pm 4.63)^{\mathrm{TC}}$ \\
\hline $\mathrm{V}_{\text {finger }} \stackrel{\ddagger}{\ddagger}\left(\mathrm{cm}^{3}\right)$ & $354( \pm 54.7)^{\mathrm{TC}}$ & $325( \pm 76.8)^{\mathrm{TC}}$ & $434( \pm 91.6)^{\mathrm{TC}}$ & $305( \pm 116.00))^{\mathrm{TC}}$ & $417( \pm 48.90)$ TC & $280( \pm 74.9)^{\mathrm{TC}}$ & $467( \pm 67.3)^{\mathrm{TC}}$ & $359( \pm 81.9)^{\mathrm{TC}}$ \\
\hline \multirow[t]{2}{*}{ Ratio $_{\text {finger }} \neq(-)$} & $0.073( \pm 0.004) \mathrm{TC}$ & $0.078( \pm 0.01) \mathrm{TC}$ & $0.068( \pm 0.005)^{C}$ & $0.072( \pm 0.007) \mathrm{C}$ & $0.078( \pm 0.015)^{\mathrm{T}}$ & $0.081( \pm 0.005)^{\mathrm{T}}$ & $0.078( \pm 0.005)^{\mathrm{T}}$ & $0.082( \pm 0.007)^{\mathrm{T}}$ \\
\hline & \multicolumn{8}{|c|}{ Phenology } \\
\hline DTF (days) & $293( \pm 14.8)^{\mathrm{TC}}$ & $297( \pm 17.8)^{\mathrm{TC}}$ & $405( \pm 87.1)^{\mathrm{C}}$ & $406( \pm 57.6)^{\mathrm{C}}$ & $264( \pm 32) \mathrm{TC}$ & $258( \pm 31) \mathrm{TC}$ & $447( \pm 81)^{\mathrm{TC}}$ & $487( \pm 80)^{\mathrm{TC}}$ \\
\hline \multirow[t]{2}{*}{ DTH (days) } & $474( \pm 6.03)^{\mathrm{TC}}$ & $511( \pm 103)^{\mathrm{TC}}$ & $546( \pm 113)^{\mathrm{TC}}$ & $662( \pm 164)^{\mathrm{TC}}$ & $420( \pm 31.2) \mathrm{C}$ & $410( \pm 31.8)^{\mathrm{C}}$ & $612( \pm 54)^{\mathrm{TC}}$ & $636( \pm 56)^{\mathrm{TC}}$ \\
\hline & \multicolumn{8}{|c|}{ Growth Rates } \\
\hline $\mathrm{V}_{\text {rate }}\left(\mathrm{L} \mathrm{day}^{-1}\right)$ & $0.203( \pm 0.0331)^{\mathrm{TC}}$ & $0.156( \pm 0.0251)^{\mathrm{TC}}$ & $0.398( \pm 0.0874)^{\mathrm{TC}}$ & $0.297( \pm 0.0698)^{\mathrm{TC}}$ & $0.308( \pm 0.0418)^{\mathrm{TC}}$ & $0.320( \pm 0.0520){ }^{\mathrm{TC}}$ & $0.183( \pm 0.0491)^{\mathrm{TC}}$ & $0.111( \pm 0.0307)^{\mathrm{TC}}$ \\
\hline \multirow{3}{*}{$\mathrm{B}_{\text {rate }}\left(\mathrm{kg} \mathrm{day}^{-1}\right)$} & $0.144( \pm 0.0271)^{\mathrm{T}}$ & $0.103( \pm 0.0201)^{\mathrm{T}}$ & $0.266( \pm 0.0856)^{\mathrm{TC}}$ & $0.167( \pm 0.141)$ & $0.333( \pm 0.0419) \mathrm{TC}$ & $0.193( \pm 0.0460))^{\mathrm{TC}}$ & $0.315( \pm 0.0462)^{\mathrm{TC}}$ & $0.205( \pm 0.0369)^{\mathrm{TC}}$ \\
\hline & \multirow{2}{*}{\multicolumn{6}{|c|}{ Huti Green Bell }} & Naing & \\
\hline & & & & & & GN-FI & \multicolumn{2}{|c|}{ GN-RF } \\
\hline FCD (C2-C1) (days) & \multirow{2}{*}{\multicolumn{2}{|c|}{$\begin{array}{l}243( \pm 82.8)^{\mathrm{C}} \\
222(126)^{\mathrm{TC}}\end{array}$}} & \multirow{2}{*}{\multicolumn{2}{|c|}{$\begin{array}{l}237( \pm 55.2)^{\mathrm{C}} \\
282(53.7)^{\mathrm{TC}}\end{array}$}} & \multirow{2}{*}{\multicolumn{2}{|c|}{$\begin{array}{c}307( \pm 69)^{\mathrm{TC}} \\
315( \pm 43.1)^{\mathrm{TC}}\end{array}$}} & \multirow{2}{*}{\multicolumn{2}{|c|}{$\begin{array}{c}360( \pm 78)^{\mathrm{TC}} \\
332( \pm 590) \mathrm{TC}\end{array}$}} \\
\hline HCD (C2-C1) (days) & & & & & & & & \\
\hline
\end{tabular}

$A B \overline{G V D}$, aboveground vegetative dry matter includes pseudostem, petiole and leaf dry matter. BunchF, fresh bunch weight; $\mathrm{N}_{\text {hand }}$, number of hands on a bunch; $\mathrm{N}_{\text {finger }}$, number of fingers on a bunch. Phenology data: DTF, days to flower emergence; DTH, days to harvest; Moisture (precipitation and irrigation) and ET0 Ratios: between planting and flowering ( $\mathrm{R}_{\mathrm{PF}}$ ), flowering and harvest $\left(\mathrm{R}_{\mathrm{FH}}\right)$ and planting and harvest $\left(\mathrm{R}_{\mathrm{PH}}\right)$; Cycle duration: FCD, flower cycle duration, the time (in days) between flower emergence of $\mathrm{C} 1$ and flower emergence of flowering and harvest $\left(\mathrm{R}_{\mathrm{FH}}\right)$ and planting and harvest $\left(\mathrm{R}_{\mathrm{PH}}\right)$; Cycle duration: FCD, flower cycle duration, the time (in days) between flower emergence of $\mathrm{C1}$ and flower emergence of Grande Naine (GN). ${ }^{+}$: parameter at flowering, $\neq$: parameter at harvest. T: notes difference between treatment FI and RF (within a cycle and cultivar) ( $\left.p=0.05\right)$, C: notes difference between cycles (within a moisture treatment and cultivar) $(p=0.05)$. 
The average pseudostem growth rate $\left(\mathrm{V}_{\text {rate }}\right.$, Table 1$)$, an indicator of vegetative growth was analyzed in terms of $\mathrm{R}_{\mathrm{PF}}$, an indicator of moisture between planting and flowering. Linear models were created with $V_{\text {rate }}$ as a dependent variable and $R_{P F}$ as the independent variable for each cultivar and cycle (Table 3$)$. The average bunch growth rate ( $\mathrm{B}_{\text {rate, }}$ Table 1$)$ of plants in the field was analyzed in terms of $\mathrm{V}_{\text {rate }}$ (the earlier vegetative growth rate) and $\mathrm{R}_{\mathrm{FH}}$, an indicator of moisture between flowering and harvest. Linear models were created with $B_{\text {rate }}$ as a dependent variable and $V_{\text {rate }}$ and $R_{F H}$ as the independent variable for each cultivar and cycle. Effects of the parameters were significant if coefficients in the linear models were significant (Table 3).

\subsection{Allometric Regression}

Two types of allometric relationships were created corresponding to the different objectives: (i) models for estimating vegetative biomass (ABGVD and cormD), and (ii) models for forecasting fresh bunch weights (bunchF) from flowering onwards. Since allometry specifies how growth and size in plants or plant components is related to their allocated biomass, only parameters measured on a plant were put into the allometric equations.

\subsubsection{Non-Destructive Vegetative Biomass Estimation}

Plants sampled during harvest and periodic destructive sampling were used for ABGVD allometry. Data spanned multiple cycles C1, C2, and C3 with plants of different sizes. Vegetative parameters at the moment of destructive sampling $\left(\mathrm{V}_{\text {pseudo }}, \mathrm{LAI}\right)$ and bunch parameters $\left(\mathrm{N}_{\text {finger }}, \mathrm{N}_{\text {hand }}, \mathrm{V}_{\text {finger }}\right.$,

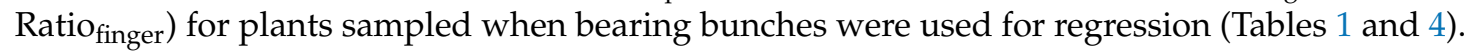

Plants sampled during periodic destructive sampling were used for cormD allometry. CormD was regressed on vegetative parameters at the moment of sampling $\left(\mathrm{V}_{\text {pseudo, }}\right.$, LAI), but given the lack of replications of bunch bearing plants at destructive sampling, other parameters were not included (Table 4).

\subsubsection{Bunch Fresh Weight Forecast}

Plants with bunches ready for harvest (sampled at harvest) were used for bunchF regression. Only C1 and C2 were used, as C3 was not yet ready for harvest. As early estimation is of interest, the bunchF was regressed sequentially on predictors that can be grouped according to the period when first measurement is possible. Predictors were organized in three groups: Early predictors, relating to parameters at flowering: days to flowering (DTF), $\mathrm{V}_{\text {pseudo,Flower, }} \mathrm{LAI}_{\text {Flower }}$; Middle predictors, describing bunch characteristics that do not change during fruit filling: $\mathrm{N}_{\text {hand }}$ and $\mathrm{N}_{\text {finger }}$; and late predictors, describing bunch parameters that change up until the moment of harvest: Ratio finger and $\mathrm{V}_{\text {finger }}$ (Table 4). In addition to parameters measured on the main plant, the size of the sucker at flowering of the main plant $\left(\mathrm{V}_{\text {pseudo,flowers }}\right)$ on the same mat was also used as a predictor in regressions (Table 4).

\subsubsection{Regression Approach}

Observations used in regression analysis were subjected to a principal component analysis to identify multivariate outliers. Scatterplots in the first four PCs were made, and observations where PCA scores lay outside the $95 \%$ confidence interval (95\%CI) ellipse for treatment $\times$ cultivar group were removed.

First, multiple linear regression models were created for FI plants to determine the best model form for each cultivar (Table 4). Estimation of biomass and yield, as a rule rather than an exception, is heteroscedastic. As transforming variables leads to non-intuitive relations, heteroscedasticity was dealt with through weighted least squares regression (WLS) [7]. After WLS regression, residual plots were checked to confirm whether WLS models became homoscedastic. The regression models were compared to assess the most suitable linear regression form. Criteria used in model selection were the adjusted correlation coefficient $\left(R^{2}\right.$ adj $)$, relative root mean square error (RRMSE), and the Akaike 
information criterion (AIC). AIC can only be compared on models with similar number of observations. Whenever multiple predictors needed to be retained in the model, variance inflation factors (VIF) were checked as correlated predictors might lead to collinearity. Model performance was classified on RRMSE values as excellent $(\leq 10 \%)$, good $(10 \%<$ RRMSE $\leq 20 \%)$, fair $(20 \%<$ RRMSE $\leq 30 \%)$, and poor $(>30 \%)$ [34]. Next to goodness of fit criteria, the practicality of predictors in the field was also considered in choosing the final model form.

After determining the best model forms for FI plants, pooled (combining data from cultivars and treatments) and specific regression models (separating data across cultivars and treatments) were created (Table 5). Specific regression models were compared between irrigation treatments and cultivars. Comparison of specific regression models were done using three methods. In the first method, the $95 \% \mathrm{CI}$ for parameter coefficients in the regressions were compared across groups to evaluate overlap. If $95 \% \mathrm{CI}$ overlapped, models were not different. The second method used an analysis of covariance (ANCOVA) by adding categorical variables treatment and cultivar as dummy variables in the linear regression models. It was assessed whether the parameter coefficients in the models were significantly different between the groups, or whether they could be estimated by a common coefficient [7]. The third method used FI models for predicting both FI and RF data. These predicted values $\left(\mathrm{x}_{\mathrm{i}}\right)$ were plotted against observed values $\left(\mathrm{y}_{\mathrm{i}}\right)$, whereby the regression line was evaluated for bias. The bias $\%$ for each group (treatment $x$ cultivar) was calculated as

$$
\text { bias } \%=\left(\sum_{i=1}^{n} \frac{x_{i}-y_{i}}{x_{i}}\right) \times \frac{100}{n},
$$

with $x_{i}$ and $y_{i}$ being the observed and predicted values for the ith observation and $n$ is the number of observations [9]. If the bias\% is positive, the models underestimate reality and if the bias\% is negative, models overestimate reality. 
Table 3. Linear regression model output for average pseudostem growth rate until flowering $\left(\mathrm{V}_{\text {rate, }} \mathrm{L}_{\text {day }}{ }^{-1}\right)$, and average bunch growth rate between flower emergence and harvest $\left(\mathrm{B}_{\text {rate }}, \mathrm{kg} \mathrm{day}^{-1}\right)$ in terms of added moisture and reference evapotranspiration. Models are characterized by parameter $\mathrm{x}$, intercept 'a' and slope ' $b$ ' and ' $c$ ' as $y=a+b \times x+c \times y . V_{\text {rate }}$ and $B_{\text {rate }}$ models note models with y being $V_{\text {rate }}$ and $B_{\text {rate }}$ respectively. P indicates pooled model, $S$ indicates specific model. Both indicates pooling of data across cultivars and/or cycles. FI notes full irrigation and RF notes Rainfed. $R_{\mathrm{PF}}$ and $\mathrm{R}_{\mathrm{FH}}$ note ratio of cumulative added moisture (rainfall and precipitation) to cumulative ET0 between planting and flowering, and flowering and harvest respectively.

\begin{tabular}{|c|c|c|c|c|c|c|c|c|c|c|c|c|c|c|c|c|}
\hline & & & \multicolumn{7}{|c|}{ Model Coefficients } & \multicolumn{7}{|c|}{ Goodness of Fit Characteristics } \\
\hline \multicolumn{17}{|c|}{ Vrate Models } \\
\hline Data & Cultivar & Cycle & Parameters & Intercept (a) & $95 \% \mathrm{CI}$ & Coefficient (b) & $95 \% \mathrm{CI}$ & Coefficient (c) & $95 \% \mathrm{CI}$ & $\mathbf{n}$ & df & $R^{2}$ adj & AIC & RMSE & RRMSE & $p$-Value \\
\hline $\mathrm{P}$ & Huti Green & Both & $\mathrm{R}_{\mathrm{PF}}$ & -0.06 & $\begin{array}{l}(-0.11 ; \\
-0.01)\end{array}$ & 0.36 & $(0.28 ; 0.43)$ & & & 66 & 2 & 0.59 & -238.86 & 0.041 & 0.20 & $3.09 \times 10^{-14}$ \\
\hline $\mathrm{S}$ & & $\mathrm{C} 1$ & $\mathrm{R}_{\mathrm{PF}}$ & ns & & 0.26 & $(0.25 ; 0.27)$ & & & 54 & 1 & 0.97 & -220.75 & 0.031 & 0.17 & $2.57 \times 10^{-43}$ \\
\hline $\mathrm{S}$ & & $\mathrm{C} 2$ & $\mathrm{R}_{\mathrm{PF}}$ & ns & & 0.30 & $(0.27 ; 0.34)$ & & & 12 & 1 & 0.97 & -27.72 & 0.065 & 0.19 & $1.41 \times 10^{-9}$ \\
\hline $\mathrm{P}$ & Grande Naine & Both & $\mathrm{R}_{\mathrm{PF}}$ & -0.04 & $\begin{array}{l}(-0.07 ; \\
-0.01)\end{array}$ & 0.22 & $(0.19 ; 0.25)$ & & & 99 & 2 & 0.65 & -273.66 & 0.067 & 0.31 & $4.88 \times 10^{-24}$ \\
\hline $\mathrm{S}$ & & $\mathrm{C} 1$ & $\mathrm{R}_{\mathrm{PF}}$ & 0.41 & $(0.19 ; 0.64)$ & ns & & & & 40 & 2 & -0.00 & -129.28 & 0.045 & 0.14 & $3.65 \times 10^{-1}$ \\
\hline $\mathrm{S}$ & & $\mathrm{C} 2$ & $\mathrm{R}_{\mathrm{PF}}$ & 0.03 & $(0 ; 0.06)$ & 0.11 & $(0.08 ; 0.14)$ & & & 59 & 2 & 0.49 & -219.96 & 0.038 & 0.26 & $4.45 \times 10^{-10}$ \\
\hline \multicolumn{17}{|c|}{ Brate Models } \\
\hline & Cultivar & Cycle & Parameters & Intercept (a) & $95 \% \mathrm{CI}$ & Coefficient (b) & $95 \% \mathrm{CI}$ & Coefficient (c) & $95 \% \mathrm{CI}$ & $\mathbf{n}$ & df & $R^{2}$ adj & AIC & RMSE & RRMSE & $p$-Value \\
\hline $\mathrm{P}$ & Huti Green & Both & Vrate, $R_{\mathrm{FH}}$ & ns & & 0.73 & $(0.70 ; 0.77)$ & ns & & 65 & 1 & 0.96 & -233.43 & 0.053 & 0.38 & $4.34 \times 10^{-48}$ \\
\hline $\mathrm{s}$ & & $\mathrm{C} 1$ & Vrate, $\mathrm{R}_{\mathrm{FH}}$ & ns & & 0.53 & $(0.37 ; 0.69)$ & 0.01 & $(0 ; 0.03]$ & 54 & 2 & 0.97 & -264.12 & 0.020 & 0.16 & $2.91 \times 10^{-42}$ \\
\hline S & & $\mathrm{C} 2$ & Vrate, $\mathrm{R}_{\mathrm{FH}}$ & ns & & 0.58 & $(0.39 ; 0.77)$ & ns & & 11 & 1 & 0.80 & -13.63 & 0.120 & 0.60 & $4.91 \times 10^{-05}$ \\
\hline $\mathrm{P}$ & Grande Naine & Both & Vrate, $\mathrm{R}_{\mathrm{FH}}$ & ns & & 0.56 & $(0.50 ; 0.65)$ & 0.14 & $(0.12 ; 0.15)$ & 99 & 2 & 0.98 & -340.63 & 0.043 & 0.17 & $2.32 \times 10^{-85}$ \\
\hline $\mathrm{s}$ & & $\mathrm{C} 1$ & Vrate, $\mathrm{R}_{\mathrm{FH}}$ & ns & & 0.42 & $(0.34 ; 0.50)$ & 0.19 & $(0.16 ; 0.22)$ & 40 & 2 & 0.98 & -139.73 & 0.004 & 0.14 & $3.92 \times 10^{-33}$ \\
\hline $\mathrm{s}$ & & $\mathrm{C} 2$ & Vrate, $\mathrm{R}_{\mathrm{FH}}$ & 0.05 & $(0.02 ; 0.09)$ & 0.91 & $(0.76 ; 1.06)$ & 0.06 & $(0.03 ; 0.08)$ & 59 & 3 & 0.78 & -232.16 & 0.323 & 0.13 & $9.58 \times 10^{-20}$ \\
\hline
\end{tabular}


Table 4. Regression models for fully irrigated plants of Huti Green Bell and Grande Naine, with goodness of fit characteristics. Models are multiple linear regression models with each parameter ' $x$ ' characterized by intercept ' $a$ ' and slope ' $b$ ': $y=a+b \times x$. ABGVD notes the aboveground vegetative dry biomass (leaves, petioles, and pseudostem), cormD notes the corm dry biomass, and bunchF notes the fresh bunch weight. Additional parameters are explained in Table 1 and given underneath the table.

\begin{tabular}{|c|c|c|c|c|c|c|c|c|c|c|c|c|c|}
\hline \multirow[b]{3}{*}{ Model } & \multirow[b]{3}{*}{ Parameters } & \multicolumn{6}{|c|}{ Huti Green Bell } & \multicolumn{6}{|c|}{ Grande Naine } \\
\hline & & \multicolumn{12}{|c|}{ ABGVD } \\
\hline & & $\mathrm{n}$ & df & $R^{2}$ adj & AIC & RRMSE & $p$-Value & $\mathrm{n}$ & $\mathrm{df}$ & $R^{2}$ adj & AIC & RRMSE & $p$-Value \\
\hline $\operatorname{Lm} .1^{x}$ & $\mathrm{~V}_{\text {pseudo }}$ & 91 & 2 & 0.92 & 221.22 & 0.14 & $5.62 \times 10^{-52}$ & 221 & 2 & 0.88 & 480.4 & 0.14 & $7.30 \times 10^{-102}$ \\
\hline $\mathrm{Lm} .2$ & LAI & 88 & 2 & 0.79 & 297.89 & 0.22 & $5.16 \times 10^{-31}$ & 214 & 2 & 0.92 & 573.2 & 0.19 & $1.20 \times 10^{-116}$ \\
\hline Lm.3 & $\mathrm{V}_{\text {pseudo, }}$ LAI & 88 & 3 & 0.93 & 192.41 & 0.13 & $1.70 \times 10^{-51}$ & 213 & 3 & 0.93 & 379.0 & 0.11 & $1.30 \times 10^{-124}$ \\
\hline Lm. 4 & $\mathrm{~N}_{\text {finger }}, \mathrm{N}_{\text {hand }}$ & 62 & 3 & 0.68 & 209.93 & 0.22 & $1.32 \times 10^{-15}$ & 138 & 3 & 0.19 & 475.5 & 0.27 & $3.13 \times 10^{-7}$ \\
\hline Lm.5 & $\mathrm{V}_{\text {pseudo, }}, \mathrm{N}_{\text {finger }}, \mathrm{N}_{\text {hand }}$ & 62 & 3 & 0.99 & 111.47 & 0.12 & $1.16 \times 10^{-60}$ & 138 & 3 & 0.99 & 308.1 & 0.14 & $4.81 \times 10^{-124}$ \\
\hline Lm.6 & $\mathrm{V}_{\text {finger }}$, Ratio finger & 58 & 3 & 0.29 & 236.14 & 0.31 & $2.81 \times 10^{-5}$ & 144 & 3 & 0.07 & 521.2 & 0.29 & $3.22 \times 10^{-3}$ \\
\hline \multirow[t]{2}{*}{$\mathrm{Lm} .7$} & $\begin{array}{c}\mathrm{V}_{\text {pseudo, }}, \text { Ratio } \\
\mathrm{N}_{\text {hand }}\end{array}$ & 56 & 4 & 0.90 & 116.74 & 0.12 & $3.59 \times 10^{-27}$ & 137 & 4 & 0.90 & 116.7 & 0.17 & $3.59 \times 10^{-27}$ \\
\hline & & \multicolumn{12}{|c|}{ CormD } \\
\hline Model & Parameters & $\mathrm{n}$ & $\mathrm{df}$ & $R^{2}$ adj & AIC & RRMSE & $p$-Value & $\mathrm{n}$ & $\mathrm{df}$ & $R^{2}$ adj & AIC & RRMSE & $p$-Value \\
\hline $\operatorname{Lm} .1^{x}$ & $\mathrm{~V}_{\text {pseudo }}$ & 21 & 2 & 0.94 & 72.73 & 0.24 & $1.80 \times 10^{-13}$ & 36 & 2 & 0.54 & 210.38 & 0.33 & $2.19 \times 10^{-7}$ \\
\hline Lm.2 & LAI & 14 & 2 & 0.71 & 83.14 & 0.75 & $9.95 \times 10^{-5}$ & 35 & 2 & 0.36 & 214.67 & 0.39 & $7.35 \times 10^{-5}$ \\
\hline \multirow[t]{2}{*}{ Lm.3 } & $\mathrm{V}_{\text {pseudo, }}, \mathrm{LAI}$ & 14 & 3 & 0.97 & 59.62 & 0.22 & $2.20 \times 10^{-9}$ & 34 & 3 & 0.53 & 199.99 & 0.34 & $2.87 \times 10^{-6}$ \\
\hline & & \multicolumn{12}{|c|}{ BunchF } \\
\hline Model & Parameters & $\mathrm{n}$ & df & $R^{2}$ adj & AIC & RRMSE & $p$-Value & $\mathrm{n}$ & df & $R^{2}$ adj & AIC & RRMSE & $p$-Value \\
\hline $\operatorname{Lm} .1^{x}$ & $V_{\text {pseudo,Flower }}$ & 40 & 2 & 0.70 & 228.08 & 0.12 & $1.42 \times 10^{-11}$ & 54 & 2 & 0.43 & 372.01 & 0.15 & $4.50 \times 10^{-8}$ \\
\hline Lm.2 & LAI $_{\text {Flower }}$ & 41 & 2 & 0.62 & 258.56 & 0.17 & $6.17 \times 10^{-10}$ & 54 & 2 & 0.22 & 383.2 & 0.17 & $1.96 \times 10^{-4}$ \\
\hline Lm.3 & DTF & 41 & 2 & 0.32 & 268.02 & 0.22 & $7.71 \times 10^{-5}$ & 55 & 2 & -0.01 & 406.85 & 0.20 & $4.83 \times 10^{-1}$ \\
\hline Lm.4 & $\mathrm{V}_{\text {pseudo,Flower, }}$ DTF & 40 & 3 & 0.69 & 229.76 & 0.12 & $1.20 \times 10^{-10}$ & 54 & 3 & 0.42 & 373.99 & 0.15 & $3.48 \times 10^{-7}$ \\
\hline Lm.5 & $\mathrm{V}_{\text {pseudo,Flower }}$ DTF, LAI Flower & 38 & 4 & 0.60 & 220.54 & 0.13 & $1.93 \times 10^{-7}$ & 54 & 4 & 0.57 & 360.48 & 0.13 & $5.90 \times 10^{-10}$ \\
\hline Lm.6 & $\mathrm{V}_{\text {pseudo,flowerS }}$ & 38 & 2 & -0.01 & 257.52 & 0.25 & $4.97 \times 10^{-1}$ & 52 & 2 & -0.02 & 381.38 & 0.20 & $6.66 \times 10^{-1}$ \\
\hline Lm.7 & $\mathrm{V}_{\text {pseudo,flower, }}, \mathrm{Vpseudo}$,flowerS & 38 & 3 & 0.63 & 218.83 & 0.14 & $1.24 \times 10^{-8}$ & 52 & 3 & 0.48 & 361.57 & 0.14 & $4.22 \times 10^{-8}$ \\
\hline Lm.8 & $\begin{array}{l}\mathrm{V}_{\text {pseudo,Flower }}, \mathrm{DTF}, \mathrm{N}_{\text {finger }} \\
\mathrm{N}_{\text {hand }}\end{array}$ & 35 & 5 & 0.64 & 204.24 & 0.12 & $3.31 \times 10^{-7}$ & 37 & 5 & 0.65 & 248.92 & 0.13 & $8.38 \times 10^{-8}$ \\
\hline Lm.9 & $\mathrm{V}_{\text {pseudo,Flower }}, \mathrm{V}_{\text {finger }}$ & 36 & 3 & 0.80 & 191.12 & 0.11 & $1.05 \times 10^{-12}$ & 40 & 3 & 0.56 & 277.63 & 0.14 & $8.44 \times 10^{-8}$ \\
\hline Lm.10 & $\begin{array}{l}\mathrm{V}_{\text {pseudo, Flower, }}, \mathrm{V}_{\text {finger }} \text {, } \\
\text { Ratiofinger }\end{array}$ & 36 & 4 & 0.80 & 192.48 & 0.11 & $6.59 \times 10^{-12}$ & 40 & 4 & 0.60 & 276.25 & 0.14 & $7.81 \times 10^{-8}$ \\
\hline Lm.11 & $\begin{array}{l}\mathrm{V}_{\text {pseudo, Flower, }} \text { DTF, } \mathrm{N}_{\text {finger }} \\
\mathrm{N}_{\text {hand }}, \mathrm{V}_{\text {finger }}\end{array}$ & 34 & 6 & 0.81 & 183.17 & 0.10 & $3.92 \times 10^{-10}$ & 37 & 6 & 0.78 & 234.28 & 0.10 & $1.88 \times 10^{-10}$ \\
\hline
\end{tabular}

DTF: days to flowering, LAI: leaf area index at sampling, LAI flower: leaf area index at flower emergence, $\mathrm{N}_{\text {finger }}$ : number of fingers per hand, $\mathrm{N}_{\text {hand }}$ : number of hands per bunch, Ratio finger: ratio between finger radius to finger length, Vpseudo: pseudostem volume at sampling, VpseudoFlower: pseudostem volume at flower emergence, VpseudoflowerS: pseudostem volume of sucker at flower emergence Vegetative predictors: $\mathrm{V}_{\text {pseudo,flower }}, \mathrm{LAI}_{\text {flower }} ;$ Predictors measured on bunch after emergence: $\mathrm{N}_{\text {finger }}, \mathrm{N}_{\text {hand }} ;$ Predictors measured at bunch maturity: $\mathrm{V}_{\text {finger }}$, Ratio ${ }_{\text {finger }}$; Predictors measured on sucker at flowering of main plant: $\mathrm{V}_{\text {pseudo,flowers. }}{ }^{\times}$Selected model. 
Table 5. Linear regression model comparison. ABGVD notes aboveground vegetative dry biomass, cormD notes corm dry biomass and bunchF notes bunch fresh biomass. Models are characterized by parameter $\mathrm{x}$, intercept ' $\mathrm{a}$ ' and slope ' $\mathrm{b}$ ' as $\mathrm{y}=\mathrm{a}+\mathrm{b}^{*} \mathrm{x}$. P indicates pooled model, $\mathrm{S}$ indicates specific model. Both indicates pooling of data across cultivars and/or treatments. FI notes full irrigation and RF notes Rainfed. $V_{\text {pseudo }}$ notes pseudostem volume, $V_{\text {pseudo,flowering, }}$ notes $V_{\text {pseudo }}$ at flowering.

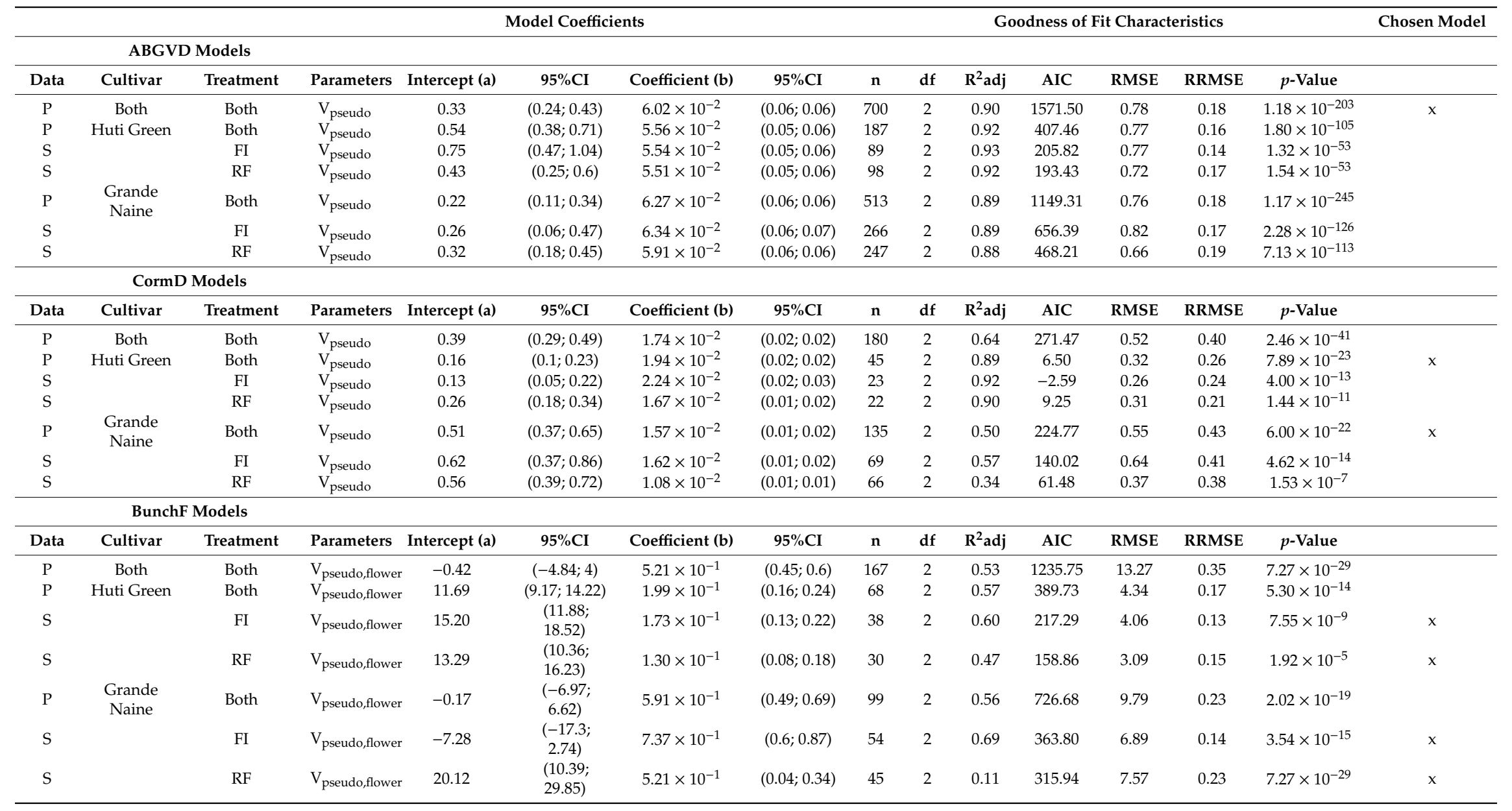




\section{Results}

\subsection{Moisture Effect on Phenology, Vegetative Growth, and Bunch Parameters}

\subsubsection{Difference in Moisture}

The onset of soil moisture differences differed between experiments (Figure 1b), due to differences in planting time (Figure 1c) resulting in rainfall periods affecting plants at a different growth stages (Figure 1a-c). In HG, moisture differences became significant during the vegetative stage of $\mathrm{C} 1$ onwards, whilst for GN, moisture differences occurred from the approximate onset of flower emergence in $\mathrm{C1}$ (Figure 1b,c) [25]. This is reflected in the ratio between water and ET0 between planting and flowering $\left(\mathrm{R}_{\mathrm{PF}}\right)$ (Table 2). $\mathrm{R}_{\mathrm{PF}}$ differed significantly between treatments in both cycles and cultivars $(p<0.05)$. $\mathrm{R}_{\mathrm{PF}}$ during HG C1 differed between treatments, but remained suboptimal for both FI (0.743 \pm 0.03$)$ and RF $(0.638 \pm 0.0404)$, indicating stressed vegetative growth. $R_{P F}$ during GN C1 was optimal in both FI (1.44 \pm 0.0213$)$ and RF (1.26 \pm 0.0448$)$, indicating non stressed vegetative growth until flowering.

During bunch development, $\mathrm{R}_{\mathrm{FH}}$ differed significantly between treatments in all cycles and cultivars $(p<0.05)$. $\mathrm{R}_{\mathrm{FH}}$ was always optimal or close to 1 in FI, but not in RF except in HG-C1 where $R F$ plants developed bunches during the rainy season $\left(R_{F H}=1.47 \pm 0.182\right)$. Contrastingly, $G N C 1$ plants developed bunches during the dry season as shown by $R_{F H}$ of $0.329( \pm 0.0239)$ for RF C1.

\subsubsection{Effect on Phenology}

Under increased soil moisture stress, a delay in banana phenology occurred, but severity of delay differed between cultivars and cycles. In HG, flowering differences were small (4 days) in C1, and not significant in C2. In GN, differences in DTF were more pronounced. RF plants flowered on average 6 days earlier in C1. In contrast, FI plants flowered on average 40 days earlier in C2 $(p<0.05)$.

Differences in harvest date (DTH) were more pronounced. In HG, FI plants were harvested 37 and 76 days earlier in $\mathrm{C} 1$ and C2, respectively. In GN, there was no difference in C1 $(p>0.05)$ but harvest occurred 34 days earlier in C2 FI plants $(p<0.05)$ (Table 2).

\subsubsection{Effect on Vegetative Growth}

Vegetative growth was affected significantly by irrigation (Table 2). FI increased parameters $H$, $\mathrm{G}_{\text {base, }}$ and $\mathrm{V}_{\text {pseudo }}$ significantly, except for GN C1 ( $p=0.24$ for H, $p=0.55$ for $\mathrm{G}_{\text {base }}$ ) as these developed under $\mathrm{R}_{\mathrm{PF}}>1$ until flowering of $\mathrm{C} 1$ (Table 2). Correspondingly, FI increased vegetative biomass ABGVD at harvest $(p<0.05)$ (Table 2$)$.

\subsubsection{Effect on Bunch Growth}

Bunch growth was also significantly affected by irrigation (Table 2). BunchF differences under irrigation were reflected in measured bunch parameters (Table 2). In HG, $\mathrm{N}_{\text {hand }}$ was increased in FI in $C 1\left(p=2.7 \times 10^{-4}\right)$, but similar in $\mathrm{C} 2(p=0.83)$. $\mathrm{N}_{\text {finger }}$ increased in both cycles, and fingers were also bigger $\left(\mathrm{V}_{\text {finger }}\right)$ under irrigation $(p<0.05)$. This resulted in significant increased bunchF under irrigation in $\mathrm{C} 1$ and $\mathrm{C} 2(p<0.05)$.

In GN, $\mathrm{N}_{\text {hand }}$ was similar in both cycles between FI and RF (Table 2), but $\mathrm{N}_{\text {finger }}$ increased under FI in C2 $\left(p=4.4 \times 10^{-4}\right)$ (Table 2). Large differences were obtained during bunch filling, as FingerF and $\mathrm{V}_{\text {finger }}$ increased under FI in both cycles $(p<0.05)$. Differences between RF and FI occurred due to differential soil moisture during bunch filling $\left(\mathrm{R}_{\mathrm{FH}}=0.333\right.$ in $\left.\mathrm{RF} C 1\right)$ from C1 onwards (Figure 1a).

\subsubsection{Effect on Growth Rates}

Combining phenology and growth parameters shows growth speeds $\left(\mathrm{V}_{\text {rate }}\right.$ and $\left.\mathrm{B}_{\text {rate }}\right)$ of plants differed significantly between the treatments (Figure 2 and Table 3). Moisture $\left(\mathrm{R}_{\mathrm{PF}}\right)$ had a significant effect on growth rates of the pseudostem $\left(\mathrm{V}_{\text {rate }}\right)$, except in GN-C1 as these plants all developed under optimal conditions $\left(R_{P F}>1\right)$. In all other groups, $R_{P F}$ had a significant $(p<0.05)$ positive effect on $V_{\text {rate }}$ 
in $\mathrm{HG}$ and GN. Both $\mathrm{V}_{\text {rate }}$ and moisture after flowering $\left(\mathrm{R}_{\mathrm{FH}}\right)$ had a significant effect on bunch growth rates $\left(B_{\text {rate }}\right)$ (Figure 2 and Table 5$)$.
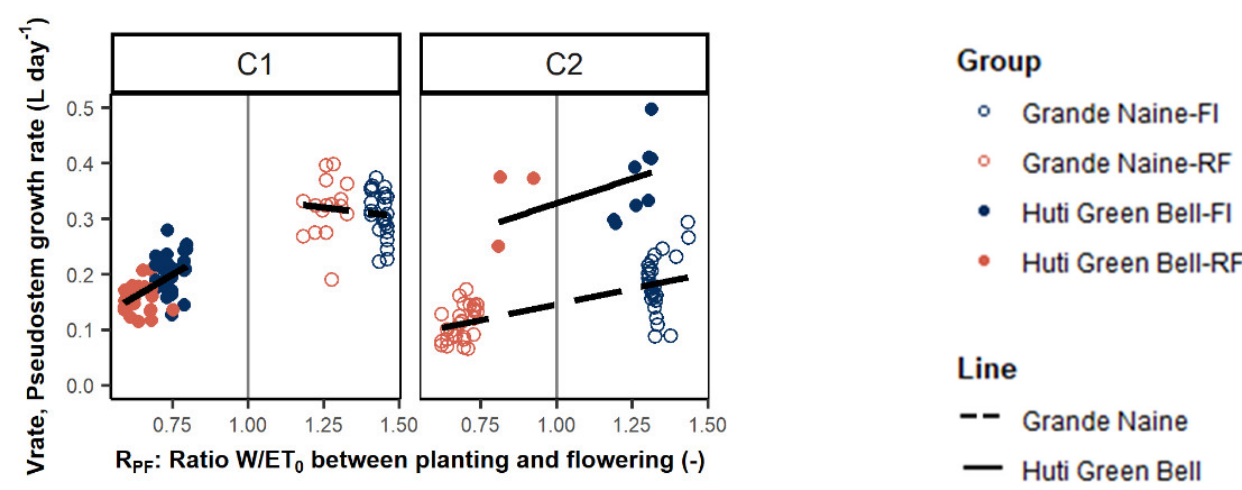

(a)

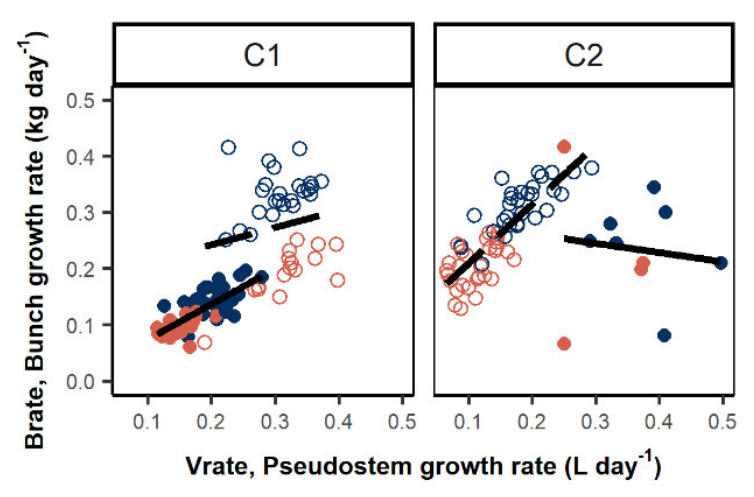

(b)

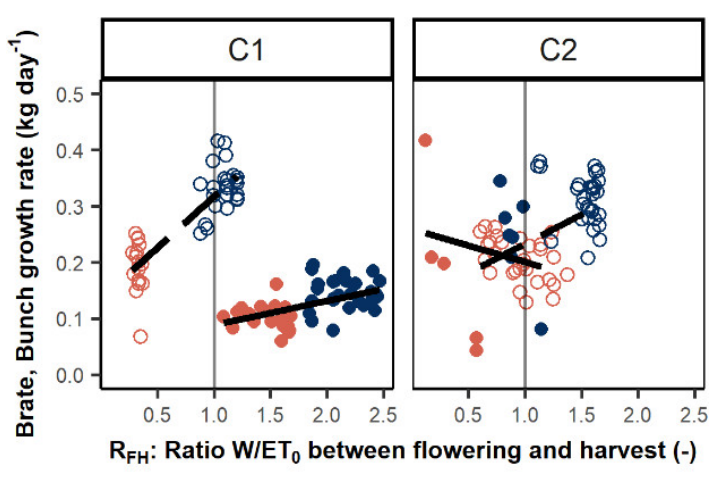

(c)

Figure 2. Effect of moisture and $\mathbf{E T}_{\mathbf{0}}$ on growth rates. (a) $\mathrm{V}_{\text {rate, }}$ pseudostem growth rate $\left(\mathrm{L} \mathrm{day}^{-1}\right)$ vs. $R_{P F}$, Ratio of cumulative water added $(\mathrm{W})$ and cumulative ET0 between planting and flowering; (b) $B_{\text {rate }}$, bunch growth rate $\left(\mathrm{kg} \mathrm{day}^{-1}\right)$ vs. $\mathrm{V}_{\text {rate }}\left(\mathrm{L} \mathrm{day}^{-1}\right)$ specifying the effect of earlier vegetative growth on bunch rates; and (c) $B_{\text {rate }} \mathrm{vs}$. $\mathrm{R}_{\mathrm{FH}}$, Ratio of cumulative water added (W) and cumulative ET0 between flowering and harvest. Dots note observations for individual plants. Lines note regression lines for each cultivar-cycle group. C1 and C2 note C1 and C2 respectively. FI notes full irrigation, RF notes rainfed.

Generally, an increase in $\mathrm{V}_{\text {rate }}$ led to an increase in $\mathrm{B}_{\text {rate, }}$ except for HG-C2. $\mathrm{V}_{\text {rate }}$ on its own does not fully explain the bunch growth rate (Table 5) as coefficients for $\mathrm{R}_{\mathrm{FH}}$ are significant in several models. This is shown clearly in GN-C1, as $\mathrm{V}_{\text {rate }}$ in FI plants is smaller, but bunch growth rates are significantly larger $(p<0.05)$ (Table 2$)$. Inclusion of $\mathrm{R}_{\mathrm{FH}}$ proves necessary for correctly assessing $\mathrm{B}_{\text {rate }}$.

\subsection{Aboveground Vegetative Dry Matter Estimation}

$\mathrm{V}_{\text {pseudo }}$ was linearly related to ABGVD in both HG and GN (Figure 3), and to all its components (leafD, petioleD, and pseudostemD) (Figure S4). VIFs higher than 5 (indicating collinearity) were not found in our models (Table 4). 


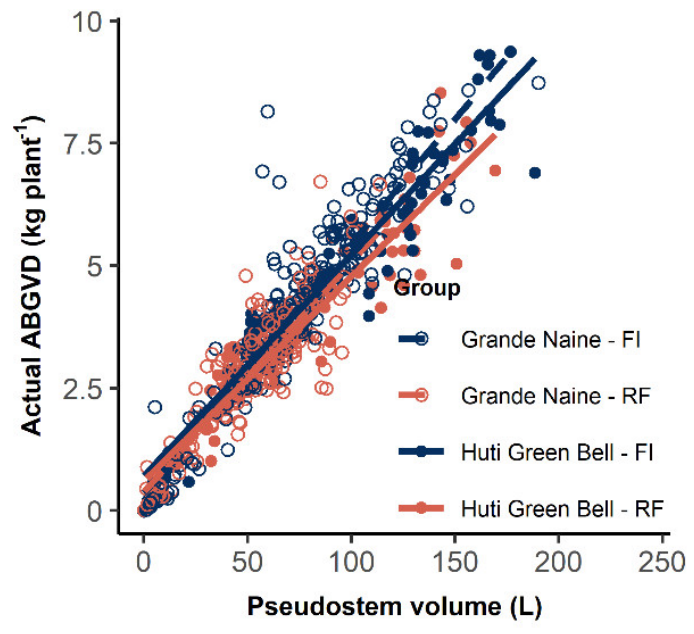

(a)

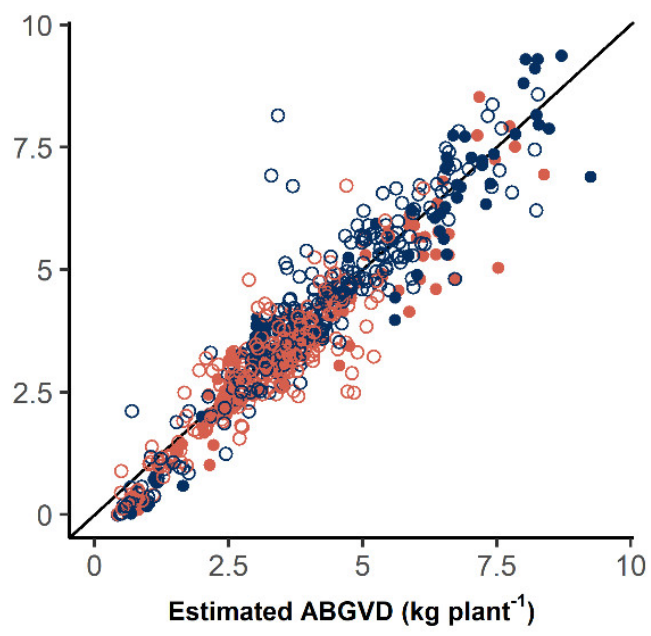

(b)

Figure 3. Aboveground vegetative dry matter (ABGVD, kg plant ${ }^{-1}$ ) models. (a) actual ABGVD vs. pseudostem volume ( $\left.\mathrm{V}_{\text {pseudo }}\right)$ at sampling (L) for Huti Green Bell (HG) and Grande Naine (GN). Regression models were specific models for treatment and cultivar as shown in Table 5; (b) Comparison of actual ABGVD (kg plant ${ }^{-1}$ ) with estimated ABGVD $\left(\mathrm{kg} \mathrm{plant}^{-1}\right)$ as obtained using the specific regression models for treatment and cultivar as shown in Table 5. FI notes full irrigation, RF notes rainfed.

Models using only $\mathrm{V}_{\text {pseudo }}$ as a predictor already had a good model fit in HG and GN $($ RRMSE $=0.14)($ Table 4$)$. Lm.1 was the best model in terms of goodness of fit, and practicality, and was used for creating pooled and specific regression models (Table 5).

Specific FI and RF models for ABGVD showed overlapping 95\%CI model coefficients for intercept and slope in both HG and GN (Table 5), but coefficients were different between treatments using the ANCOVA method. For HG, the intercept was reduced in the RF model by $0.32\left(p=8.25 \times 10^{-14}\right)$, and the slope was very slightly reduced by $5 \times 10^{-3}(p=0.014)$. For GN, there was no effect on the intercept $(p=0.13)$ and the slope was reduced by $6.07 \times 10^{-03}\left(p=4.46 \times 10^{-3}\right)$ in RF (Figure 3 and Table 5).

Comparing predictions of the FI models with RF models, led to bias $\%$ of $-92.1 \%$ (HG) and $-81.9 \%$ (GN) for FI plants and bias\% of $-44.6 \%$ (HG) and $-41.4 .0 \%$ (GN) for RF plants. Both FI and RF plants were overestimated. Small plants $(<25 \mathrm{~L})$ were overestimated in small absolute terms $\left(<1 \mathrm{~kg} \mathrm{DM} \mathrm{plant}^{-1}\right)$, but as bias $\%$ calculates the relative deviation, these had a large effect on the overall bias $\%$. Recalculating bias\% after removal of the smaller plant $(<25 \mathrm{~L})$ led to bias $\%$ of $2.07 \%(\mathrm{HG})$ and $-1.48(\mathrm{GN})$ in FI, and bias $\%$ of $-7.26 \%(\mathrm{HG})$ and $-10.1 \%(\mathrm{GN})$ in RF. Plants $<25 \mathrm{~L}$ were overestimated in both FI and RF (in small absolute terms), but plants $>25 \mathrm{~L}$ were only overestimated in RF.

Comparison of cultivar FI models showed 95\%CI model coefficients overlapped for intercept and slope (Table 5) but models were distinctly different in intercept $(p=0.01)$ and slope $\left(p=8.89 \times 10^{-4}\right)$ following ANCOVA.

As $95 \% \mathrm{CI}$ for coefficients overlapped between treatments and cultivars, the differences although significant, may be small in practice. Pooling data from both cultivars and treatments $(n=700)$ and performing the regression on this pooled data led to a good model fit $\left(R^{2}\right.$ adj $\left.=0.90, \operatorname{RMSE}=0.18\right)$, using $\mathrm{V}_{\text {pseudo }}$ as predictor (Table 5).

The model for estimating ABGVD in HG and GN becomes:

$$
\mathrm{ABGVD}=0.33+6.02 \times 10^{-2} \times \text { Vpseudo; HG and GN combined }
$$

with ABGVD, aboveground vegetative dry matter $\left(\mathrm{kg} \mathrm{DM} \mathrm{plant}^{-1}\right)$ and Vpseudo, pseudostem volume (L). 


\subsection{Corm Dry Matter Estimation}

$\mathrm{V}_{\text {pseudo }}$ was linearly related to cormD in both HG and GN (Figure 4). VIFs higher than 5 were not found in the cormD models.

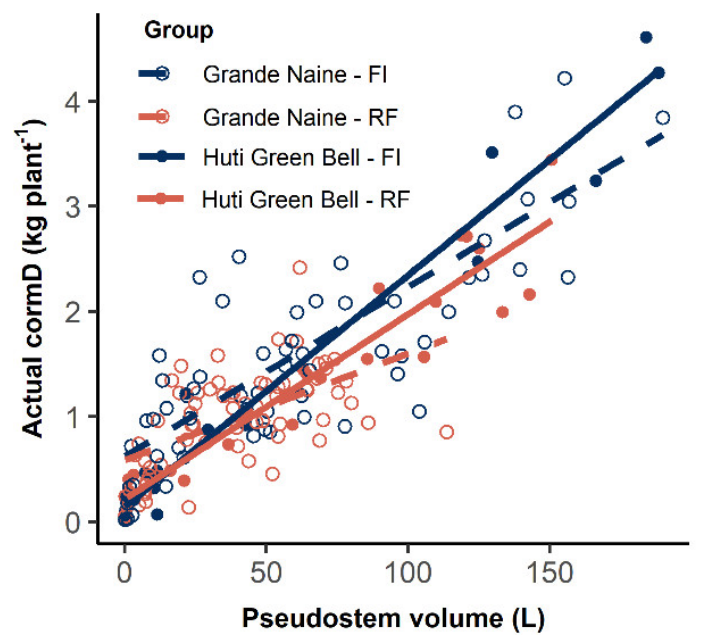

(a)

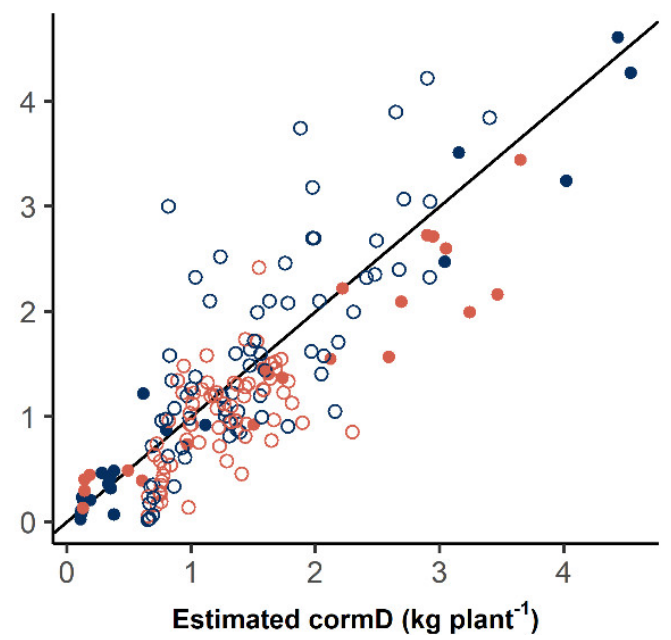

(b)

Figure 4. Corm dry matter (cormD, kg plant ${ }^{-1}$ ) models. (a) Actual cormD vs. pseudostem volume $\left(\mathrm{V}_{\text {pseudo }}\right)$ at destructive sampling (L) for Huti Green Bell (HG) and Grande Naine (GN). Regression models were specific models for treatment and cultivar as shown in Table 5; (b) Comparison of actual cormD vs. estimated cormD as obtained using the specific regression models for treatment and cultivar as shown in Table 5. FI notes full irrigation, RF notes rainfed.

Models with only $\mathrm{V}_{\text {pseudo }}$ and LAI as predictors for cormD led to a fair model performance for HG (RRMSE $=0.22)$ but poor model performance for GN (RRMSE $=0.34)$ (Table 4). Lm.1 was the best model in terms of goodness of fit and used for creating pooled and specific regression models (Table 5).

Specific FI and RF models revealed 95\%CI of coefficients overlapped for both HG and GN (Table 4), but coefficients were significantly different between treatments in both HG and GN using the ANCOVA method. For HG, RF reduced the slope by $4.01 \times 10^{-3}\left(p=5.18 \times 10^{-3}\right)$, had no effect on the intercept $(p=0.09)$ (Figure 4, Table 5). For GN, RF reduced the intercept by $0.01\left(p=2.22 \times 10^{-5}\right)$ and the slope by $5.22 \times 10^{-3}\left(p=7.59 \times 10^{-4}\right)$ (Figure 3). Due to overlap of 95\% CI, differences were not so pronounced.

All models for cormD (Tables 4 and 5) were suboptimal given the fair to poor RRMSE values, and the large variation around the 1/1 line (Figure 4). Therefore, specific model differences may not be correct, and care should be taken.

Using the specific FI regression models led to a bias\% of $-54.5 \%$ (HG) and $-156 \%$ (GN) for FI plants, and bias $\%$ of $-13.2 \%$ (HG) and $-73.2 \%$ (GN) for RF plants. Models overestimated the cormD in both treatments and cultivars. Overestimation occurred again through the influence of smaller plants. Recounting bias\% after removal of smaller plants led to a bias \% of $-3.78 \%$ (HG) and $-11.0 \%$ (GN) for FI compared to $-23.6 \%(\mathrm{HG})$ and $-39.2 \%(\mathrm{GN})$ for RF. Thereby, the RF plants were overestimated more strongly compared to the FI plants. In general, models overestimated small plants $(<25 \mathrm{~L})$, whereas bigger plants show no overestimation in HG FI, show a slight overestimation in GN FI plants, and show a large overestimation in RF plants of both cultivars.

Cultivar FI models were also different as $95 \% \mathrm{CI}$ coefficients did not overlap, and following ANCOVA, HG model intercepts were reduced $\left(p=1.77 \times 10^{-4}\right)$ and slopes increased $(p=0.05)$ compared to GN. The best models for estimating cormD for HG and GN became

$$
\text { cormD }=0.13+2.24 \times 10^{-2} \times \text { Vpseudo; HG }
$$




$$
\text { cormD }=0.62+1.08 \times 10^{-2} \times \text { Vpseudo; GN }
$$

with cormD, corm dry matter $\left(\mathrm{kg} \mathrm{DM} \mathrm{plant}^{-1}\right)$, and $\mathrm{V}_{\text {pseudo, }}$ the pseudostem volume (L).

\subsection{Bunch Weight Forecast}

ABGVD was significantly positively correlated to bunchF $(p<0.05)$ with $\mathrm{R}^{2}$ adj of 0.73 (FI) and 0.65 (RF) for HG, and $\mathrm{R}^{2}$ adj of 0.61 (FI) and 0.54 (RF) for GN. Similarly, $\mathrm{V}_{\text {pseudo, Flower was linearly related to }}$ bunchF at harvest (Figure 5). VIFs higher than 5 were not identified in the bunch models.

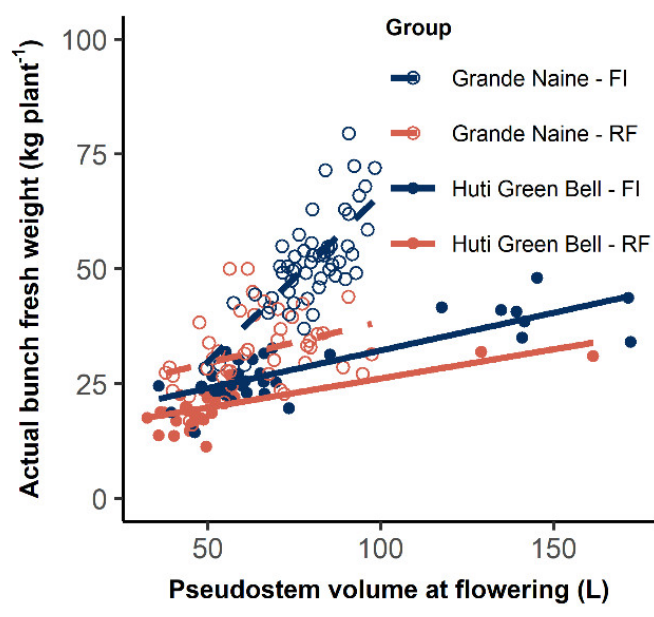

(a)

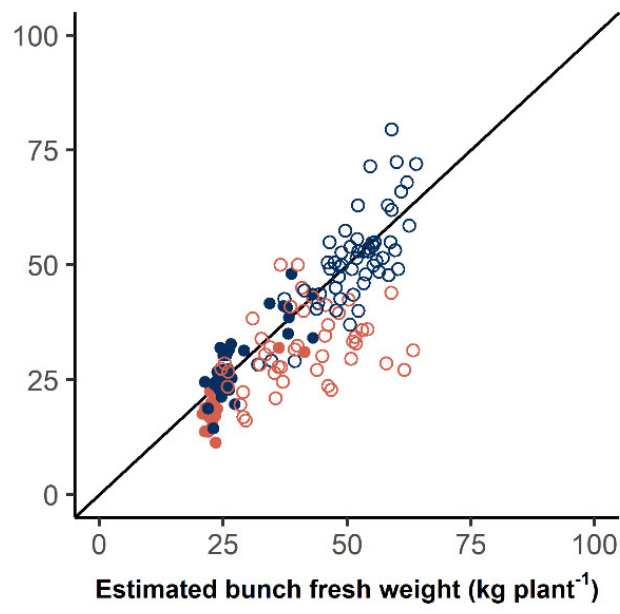

(b)

Figure 5. Bunch fresh weight (bunchF, kg plant $^{-1}$ ) models. (a) Actual bunchF vs. pseudostem volume at flowering $\left(\mathrm{V}_{\text {pseudo, Flower }}, \mathrm{L}\right)$ for Huti Green Bell (HG) and Grande Naine (GN). Regression models were specific models for treatment and cultivar as shown in Table 4; (b) Comparison of actual bunchF $\left(\mathrm{kg} \mathrm{plant}^{-1}\right)$ with estimated bunchF $\left(\mathrm{kg} \mathrm{plant}^{-1}\right)$ as obtained using the specific regression models for treatment and cultivar as shown in Table 4. FI notes full irrigation, RF notes rainfed.

Models containing only early bunch data ( $\mathrm{lm} .1$ to $\mathrm{lm} .7$ ) had RRMSE values ranging from 0.12 to 0.25 (HG) and 0.13 to 0.2 (GN) indicating good model fit (Table 4). Inclusion of data on sucker size ( $\left.\mathrm{V}_{\text {pseudo,flowers }}\right)$ did not improve the RRMSE of the models ( $1 \mathrm{~m} .6$ to $\left.1 \mathrm{~m} .7\right)$ compared to models with only $\mathrm{V}_{\text {pseudo,flower }}(\mathrm{lm} .1)$. Inclusion of data collected at later stages $(\mathrm{lm} .8$ to $\mathrm{lm} .11)$ improved model fits as RRMSE values reduced and $\mathrm{R}^{2}$ adj increased. To allow for earliest bunch estimation, model containing $V_{\text {pseudo, Flower }}(\operatorname{lm} .1)$ were retained for both $H G\left(R^{2}\right.$ adj $\left.=0.70, R R M S E=0.12\right)$ and $\mathrm{GN}\left(\mathrm{R}^{2}\right.$ adj $\left.=0.43, \mathrm{RRMSE}=0.15\right)$.

Pooled and specific regression models proved different between treatments in both HG and GN $(p<0.01)$ (Table 5). Model coefficients did not show overlap in the 95\%CI. For HG, RF led to a significantly lower intercept (ANCOVA, $p=7.18 \times 10^{-12}$ ), whilst slopes remained similar (ANCOVA, $p=0.38$ ). For GN, the intercept and slope were different between treatments $(p<0.05)$ leading to widely different relationships with $\mathrm{V}_{\text {pseudo, Flower }}$ (Figure 4, Table 4).

Using the specific FI regression models to estimate bunchF for both FI and RF plants, led to a significant overestimation of RF bunches in both HG and GN (Figure 5). The bias\% for FI plants was $-2.31 \%(\mathrm{HG})$ and $-1.74 \%(\mathrm{GN})$ and the bias\% of the RF plants was $-28.0 \%(\mathrm{HG})$ and $-24.1 \%(\mathrm{GN})$. Therefore, using FI models significantly overestimated the RF plants.

The specific models were also different between the cultivars ( $p<0.01$, Figure 5 and Table 5). Models for optimal bunch weights (FI conditions) became:

$$
\text { bunchF }=0.13+2.24 \times 10^{-2} \times \mathrm{V}_{\text {pseudo,flower }} \text { HG-FI }
$$




$$
\text { bunchF }=0.62+1.08 \times 10^{-2} \times \mathrm{V}_{\text {pseudo,flower; }} \text { GN-FI }
$$

with bunchF being fresh bunch weight $\left(\mathrm{kg} \mathrm{plant}^{-1}\right)$, and $\mathrm{V}_{\text {pseudo,flower }}$ being the pseudostem volume (L) at flowering.

\section{Discussion}

\subsection{Effect of Moisture on Vegetative and Bunch Growth}

Irrigation resulted in significant soil moisture differences (Figure 1b) affecting phenology, vegetative growth, and bunch growth (Table 2). Drought in banana induces stomatal closure, reducing transpiration and photosynthesis which reduces leaf area, leaf emission rate, and vegetative growth in general [18,25,35-37]. Drought during flower initiation may reduce $\mathrm{N}_{\text {hand }}$ per bunch and $\mathrm{N}_{\text {finger }}$ per hand [28], whereas drought after flower initiation results in suboptimal fruit filling [38].

HG plants already experienced different moisture regimes during $\mathrm{C} 1$ vegetative growth and thereby differed between FI and RF in both vegetative and bunch parameters (Table 2). GN plants developed under optimal conditions $\left(\mathrm{R}_{\mathrm{PF}}>1\right)$ until flower emergence of $\mathrm{C} 1$ [25], thereby FI and $\mathrm{RF}$ plants of $\mathrm{C} 1$ did not differ in $\mathrm{V}_{\text {pseudo, }}, \mathrm{N}_{\text {hand }}$, and $\mathrm{N}_{\text {finger }}$ (Table 2), parameters that are determined during the vegetative stage. Differences in $\mathrm{R}_{\mathrm{FH}}$ from $\mathrm{C} 1$ flowering onward (Figure $1 \mathrm{~b}$ and Table 2) led to differences in $A B G V D$, fingerF, $V_{\text {finger }}$, Ratio finger, and bunchF at harvest.

Phenology was delayed under drought depending on the severity of moisture deficit. Differences in flowering (DTF) remained small, but differences in harvest (DTH) were very pronounced with FI plants being harvested much earlier in both cycles and cultivars (Table 2). Flowering of GN C1 occurred 6 days earlier in RF plants, but $R_{P F}$ of both treatments was bigger than 1, so RF plants developed optimally until flowering. After flower emergence, $\mathrm{R}_{\mathrm{FH}}$ ratios in RF plants were significantly lower than $1(0.329 \pm 0.0239)$ delaying harvest. Differences in DTF and DTH increased in C2, as plants of C2 developed under more significant moisture stress for GN (Table 2). Environmental stress due to suboptimal soil moisture has been shown to delay floral development and increase bunch filling duration in banana plants $[18,39,40]$.

Combining absolute growth and phenology, showed effects of moisture on pseudostem $\left(\mathrm{V}_{\text {rate }}\right)$ and bunch $\left(\mathrm{B}_{\text {rate }}\right)$ growth rates (Table 3, Figure 2$) . \mathrm{V}_{\text {rate }}$ was influenced by $\mathrm{R}_{\mathrm{PF}}(p<0.05$, Table 3), although effects differ due to the size of $R_{\mathrm{PF}}$. If $R_{\mathrm{PF}}>1$, moisture covers the evaporative demand as shown in GN-C1, where $V_{\text {rate }}$ was not influenced by $R_{P F}$ as $R_{P F}$ was optimal for both RF and FI (Table 3). Only when $R_{P F}$ was less than $1, V_{\text {rate }}$ seemed to be negatively affected (Figure 2 and Table 3 ). In order to achieve fast vegetative growth rates, $R_{P F}$ should remain above 1 .

The effect of $V_{\text {rate }}$ on $B_{\text {rate }}$ was significant (Table 3), as faster $V_{\text {rate }}$ resulted in increased $B_{\text {rate }}$ (Figure 2b). Moisture after flowering $\left(\mathrm{R}_{\mathrm{FH}}\right)$ also influences $\mathrm{B}_{\text {rate }}$ significantly (Table 3, Figure 2c). $\mathrm{R}_{\mathrm{FH}}$ needs to be bigger or close to 1 to ensure optimal bunch filling (Figure 2 and Table 3). Within cycles and cultivars, we see that an increased $R_{F H}$ has the bigger $B_{\text {rate }}$ for GN and HG (except HG C2).

Moisture deficit thereby has a double effect on bunch growth. Firstly, moisture deficits during the vegetative stage $\left(R_{P F}<1\right)$ reduce the vegetative growth of the plant $\left(V_{\text {rate }}\right)$, which reduces the $B_{\text {rate }}$. During bunch filling, previously stored nutrients are translocated to fill the bunch [2-5]. Less vegetative biomass thereby indicates less translocation potential. Secondly, moisture deficits during the bunch filling stage $\left(\mathrm{R}_{\mathrm{FH}}<1\right)$ affect translocation and bunch filling [18,39], resulting in a reduced $\mathrm{B}_{\text {rate }}$. Both stages are important in the eventual outcome of the bunch weight. In order to achieve optimal growth for the pseudostem and the bunch, added moisture amounts should be compared to evaporative demands of the atmosphere. If the added moisture amounts are significantly less than the reference evapotranspiration $(R<1)$, moisture needs to be added to ensure optimal growth.

\subsection{ABGVD Estimation from Non-Destructive Observations}

$\mathrm{V}_{\text {pseudo }}$ was significantly linearly correlated to the ABGVD (Figure 3), and a good predictor for ABGVD in both HG and GN (RRMSE of 0.14) (Table 4). Height, girth, and diameters (components for 
volume estimation) are often used in biomass regression [7]. In trees, height and diameter at breast height are significantly correlated to biomass of a stand [7,41,42]. Negash et al. [8] found girth at base to be the best predictor for aboveground biomass estimation $\left(R^{2}=0.77-0.98\right)$ in Enset. Nyombi et al. [5] found girth at base to be the best predictor in development-stage specific regressions $\left(R^{2}=0.79-0.99\right)$, but height to be the best predictor of ABGVD when pooling the data across development stages $\left(R^{2}=0.98\right)$. Combining height and girth leads to a parameter describing the pseudostem (volume) in three dimensions, without leading to high co-linearity when keeping both parameters in the model [7]. $\mathrm{V}_{\text {pseudo }}$ is linked to all components of aboveground biomass (pseudostem, leaves, and petioles) in our field (Figure S4). The pseudostem is composed of tightly compacted leaf sheaths, which result from previous cumulative leaf formation. $V_{\text {pseudo }}$ was therefore also correlated to the petiole and leaf mass in our field (Figure S4) [39]. However, the number of leaves and petioles at a given time are also affected by management practices (e.g., pruning) and stress conditions, indicating correlations can differ in other plantations.

Even though $V_{\text {pseudo }}$ was affected by soil moisture deficit, the relationship between $V_{\text {pseudo }}$ and ABGVD was not influenced strongly. Specific regression models for ABGVD between treatment and cultivar differed according to ANCOVA $(p<0.05)$ (Table 4$)$, but differences were small as $95 \%$ CI for model coefficients overlapped. Pooling cultivar and treatment data led to a good model fit $\left(\mathrm{R}^{2}\right.$ adj 0.90 and RRMSE 0.18, Table 5) indicating a single ABGVD model based on $\mathrm{V}_{\text {pseudo }}$ can be used (Equation (2)).

Perhaps stress was not marked enough for ABGVD plasticity under drought as average bunches in RF plots ranged from 19.6 to $24.4 \mathrm{~kg}$ plant $^{-1}$ in $\mathrm{HG}$, and from 33.2 to $33.3 \mathrm{~kg} \mathrm{plant}^{-1}$ for GN, which are considered good yields. Nyombi et al. [5] had irrigated yields for EAHB cv. Mbwazirume ranging from 20 to $40 \mathrm{~kg} \mathrm{plant}^{-1}$, whilst Wairegi et al. [9] showed yields for different rainfed EAHB cultivars from on farm visits ranging from $2-60 \mathrm{~kg} \mathrm{plant}^{-1}$. Our yields are therefore higher compared to their lower range, hence less stress was present.

Models did overestimate small plants $(<25 \mathrm{~L})$. This overestimation might be a characteristic of the model, as the intercept was not forced through zero during modelling as this may lead to poorer goodness of fit characteristics [43]. At $V_{\text {pseudo }}$ zero, there is an overestimation of $0.54 \mathrm{~kg}$ DM plant ${ }^{-1}$ (HG) and $0.22 \mathrm{~kg} \mathrm{DM} \mathrm{plant}^{-1}(\mathrm{GN})$, which are small absolute DM values, but with a large influence on the total bias\%. Removing smaller plants reduced bias\%. Overestimation of small plants could also be due to the growing behavior of suckers. Small suckers have scale and lanceolate leaves but produce foliage leaves at approx. $1.5 \mathrm{~m}$ height $[2,44]$. Shading results in improved partitioning to aboveground structures [45] and leads to an increase in pseudostem growth to faster reach sunlight. Therefore, small plants might have a lower pseudostem density $\left(\mathrm{kg} \mathrm{DM}\right.$ volume $\left.{ }^{-1}\right)$, leading to an overestimation when presuming their density to be similar to bigger plants. Another possibility is that all smaller plants are in the vegetative stage. Nyombi et al. [5] found that vegetative aboveground biomass models differ according to plant growth stage (vegetative, flowering, or harvest). Plants in the vegetative stage had a lower ABGVD compared to plants at flowering and harvest with similar girths and heights. Pooling the data across these plant growth stages might have led to this overestimation caused by small plants, but the overestimation is small in absolute terms $\left(<1 \mathrm{~kg} \mathrm{DM} \mathrm{plant}^{-1}\right)$, still warranting the use of a general regression model as this is more practical. The general regression model to use for ABGVD estimation to be used is given in Equation (2).

\subsection{CormD Estimation from Non-Destructive Observations}

$\mathrm{V}_{\text {pseudo }}$ was linearly correlated to the belowground cormD (Figure 4). CormD models based on $\mathrm{V}_{\text {pseudo }}$ ranged from fair in HG (RRMSE $\left.=0.24\right)$ to poor in GN (RRMSE $\left.=0.33\right)$ (Table 4), making $\mathrm{V}_{\text {pseudo }}$ less suitable for cormD estimation. Nyombi et al. [5] found good exponential relationships between pseudostem girth at base and cormD $\left(\mathrm{R}^{2}=0.59-0.98\right)$ but cormD in their field ranged between $0-0.40 \mathrm{~kg} \mathrm{plant}^{-1}$, which seems low compared to our cormD values ranging from $0.09-4.27 \mathrm{~kg} \mathrm{plant}^{-1}$. Negash et al. [8] found good correlations between belowground biomass (corm and adventitious roots) 
and diameter at base for Enset $\left(R^{2}=0.75\right)$, but found no such correlation with height $\left(R^{2}=0.23-0.27\right)$. Creating power models with radius at base instead of $\mathrm{V}_{\text {pseudo }}$ did not improve model fits for cormD in both HG (RRMSE $=0.38)$ and GN (RRMSE $=0.41)$ (data not shown).

Using aboveground characteristics to describe a belowground structure has shortcomings. Parameters relating to corm dimensions (e.g., corm height and girth) are expected to considerably improve the cormD estimation, but in order to estimate these the corm needs to be excavated. Corm dimensions also vary in diameter and height with plant growth phase (vegetative, flowering, harvest) and whether the plant is in the first or second cycle [2]. The corm is a storage organ whose reserves are used for fruit growth and sucker development, whereby bunch development stage, size and the amount of produced suckers also play a role in corm biomass [2]. In our field, the variation of cormD with $\mathrm{V}_{\text {pseudo }}$ increased with cycle, thereby partitioning models in terms of cycle or plant growth phase (vegetative, flowering, harvest) might significantly improve the model. Nyombi et al. [5] found growth stage specific allometric relationships for cormD, whereby $\mathrm{R}^{2}$ reduced from the vegetative $(0.98)$ to the harvest phase (0.57), signifying increased variation with increasing growth stage.

The comparison of specific models across treatments revealed irrigation effects to be significant (ANCOVA, $p<0.05$ ), but as 95\%CI intervals overlap between specific treatment models, differences were not very pronounced (Table 4). Pooled data per cultivar did not increase RRMSE much, leading to the conclusion that cormD models are similar among $\mathrm{RF}$ and FI. It seems that at a given $\mathrm{V}_{\text {pseudo, }}$ cormD will be higher in FI than in RF plants, but given the suboptimal nature of models based on $V_{\text {pseudo }}$ we cannot be certain of the water stress effects on corm allometry. The biomass of the underground corm structure is too variable to accurately predict based on aboveground vegetative characteristics alone, and care must be taken using these relationships.

\subsection{Bunch Yield Forecast}

Vegetative growth $\left(\mathrm{V}_{\text {rate }}\right)$ was linked to bunch growth in our field ( $\left.\mathrm{B}_{\text {rate }}\right)$ (Figure 2 and Table 3$)$. Others have also shown pseudostem size significantly correlates with bunch weights: $R^{2}=0.63-0.85$ [4], $R^{2}=0.66$ [9], $R^{2}=0.57-0.7$ [5], $R^{2}=0.97-0.98$ [10]. The pseudostem size relates to bunch filling potential as assimilates are translocated during the bunch filling stage [2,4,5,46] even across ratoon plants [47]. High yields are linked to vigorous early plant growth in plantain [3].

As such, stepwise regression revealed $\mathrm{V}_{\text {pseudo, Flower }}$ to be the most important predictor of bunchF compared to other regression models ( $\mathrm{R}^{2}$ adj of 0.7 for HG and 0.43 for GN; RRMSE of 0.12 for HG and 0.15 for GN) (Table 4). Inclusion of bunch related predictors $\left(\mathrm{N}_{\text {finger }}, \mathrm{N}_{\text {hand }}, \mathrm{V}_{\text {finger }}\right)$ improved model fits as $R^{2}$ adj increased ( 0.81 for HG and 0.78 for GN) and RRMSE decreased ( 0.1 for both HG and GN $\mathrm{lm} .11$ ) (Table 5). The more parameters were included closer to bunch harvest, the better the prediction. Practically, using $\mathrm{V}_{\text {pseudo,flower }}$ as a predictor for bunchF already led to good model performance in both HG and GN FI models (RRMSE 0.13-0.14).

Bunch models based on $\mathrm{V}_{\text {pseudo,flower }}$ were very different between FI and RF, as $95 \% \mathrm{CI}$ did not overlap and following ANCOVA $(p<0.05)$. FI models performed better (RRMSE 0.13 for HG, 0.14 for GN) than RF models (RRMSE 0.15 for HG, 0.23 for GN).

These different relationships between bunchF and $\mathrm{V}_{\text {pseudo,flower }}$ under drought follow differences in bunch characteristics under RF vs. FI conditions (Table 2). Drought during flower initiation may reduce $\mathrm{N}_{\text {hand }}$ and $\mathrm{N}_{\text {finger }}$ whereas drought during bunch filling results in suboptimal fruit filling $\left(\mathrm{V}_{\text {finger }}\right)[2,18,38]$. Moisture regimes at and after flowering are thereby crucial in determining actual

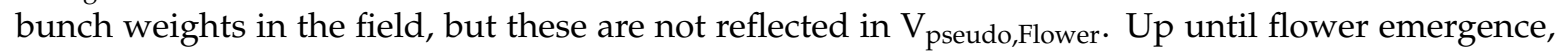
GN plants of $\mathrm{C} 1$ developed optimally in both treatments $\left(\mathrm{R}_{\mathrm{PF}}>1\right.$, Table 2) [25]. Height and girth $\left(\mathrm{V}_{\text {pseudo }}\right), \mathrm{N}_{\text {finger }}$ and $\mathrm{N}_{\text {hand }}$ did not differ at flowering $(p>0.05)$, whilst bunchF, finger, and $\mathrm{V}_{\text {finger }}$ did differ between FI and RF at harvest $(p<0.05)$ (Table 2$)$. Weight and size of the fingers determined

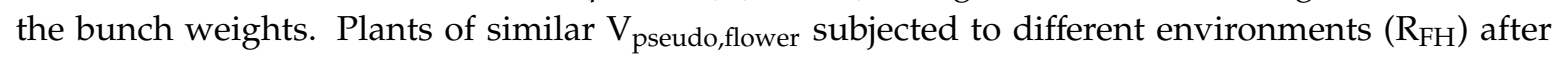
flowering (e.g., GN C1) will thereby have different bunchF at harvest, changing relationships between these parameters. 
For accurate bunch weight estimation, bunch characteristics need to be included $[9,12]$. Our models improved (RRMSE became lower) when bunch parameters were included, but this no longer allows forecasting of bunch weights as bunch characteristics (e.g., $\mathrm{V}_{\text {finger }}$ ) change until harvest.

Our FI models can be used to forecast bunch weights if plants developed without stress from flowering onwards (as $\mathrm{R}_{\mathrm{FH}}>1$ in FI). Forecasting of bunchF based on $\mathrm{V}_{\text {pseudo,Flower }}$ allows to estimate bunch 'potential' weights as in Equations (4) and (5).

To estimate 'actual' bunch weights, the environmental effects during bunch filling need to be incorporated either directly (e.g., as $\mathrm{R}_{\mathrm{FH}}$ ) or indirectly (e.g., effect of $\mathrm{R}_{\mathrm{FH}}$ on $\mathrm{V}_{\text {finger }}$ ).

The large phenotypical differences between HG and GN plants, also led to significantly different bunch weight regression curves for cultivars $(p<0.05)$. However, as cultivars were planted at a different time, differences in planting might confound differences in cultivars and we should not compare these cultivars with each other. Nyombi [5] found different allometric relationships for bunch weight for two EAHB cv Mbwazirume and Kisansa. Wairegi et al. [9] proposed the use of a general banana regression curve for estimation of EAHB bunch yields, but their results showed cultivar specific curves were characterized by lower overall variances and increased model fits. Their cultivar specific curves were similar but were significantly different in model parameters. Our results support the statement that even genetically close cultivars have different phenotypical characteristics [30].

A bunch forecast model based on $\mathrm{V}_{\text {pseudo,flower }}$ needs to include additional parameters that relate to environment conditions after flowering to properly work.

\section{Conclusions}

Irrigation and corresponding soil moisture differences had a significant effect in both HG and GN, reducing vegetative and bunch growth, and delaying phenology under RF conditions. Of the effected parameters, $V_{\text {pseudo }}$ seems a promising indicator as it is linked to both vegetative growth and bunch growth rates. The universal nature of $\mathrm{V}_{\text {pseudo }}$ as a regression parameter between the two cultivars is more valuable for future allometric studies than girth or height alone.

Allometric relationships for vegetative biomass (ABGVD and cormD) were not strongly affected by irrigation as $95 \%$ CI overlapped between FI and RF models indicating a single allometric model can be used across RF and FI plants for vegetative biomass estimation. Models did also not differ much between our phenotypically very different cultivars for $A B G V D$, hinting $V_{\text {pseudo }}$ models can be used across a range of cultivars. $V_{\text {pseudo }}$ did not prove sufficient to estimate cormD reliably, as a lot of variation remained in the underground biomass. Aboveground characteristics are therefore lacking to estimate belowground structures. For better estimation of belowground vegetative biomass, components relating to the corm dimensions can be added although these are more difficult to measure. This research shows the potential for non-destructive vegetative biomass monitoring at the field scale, and shows soil moisture to not affect vegetative allometry significantly. As biomass over time often underlies crop simulation models, this is especially useful for researchers wanting to calculate biomass in the field for calibrating such models without destroying plants.

Bunch weight (bunchF) forecasting models based on $\mathrm{V}_{\text {pseudo }}$ at flowering were significantly different between FI and RF, showing bunch weights cannot be estimated on vegetative parameters only, without including information on stress during bunch filling or bunch components. Both vegetative growth $\left(\mathrm{V}_{\text {rate }}\right)$ and moisture during bunch filling $\left(\mathrm{R}_{\mathrm{FH}}\right)$ determine bunch growth rates. Our FI models do allow prediction of bunch weights under optimal conditions after flowering $\left(R_{F H} \geq 1\right)$ and can be used to forecast bunch weight potentials based on $V_{\text {pseudo }}$ at flowering.

Supplementary Materials: The following are available online at http:/www.mdpi.com/2073-4395/10/9/1435/s1. Figure S1: Diagram of experimental design for experiment 1 and experiment 2; Figure S2: Initial plant heights for planting materials (a) Initial plant height for Huti Green Bell in cycle 1 (C1) (b) Initial plant height for Grande Naine in C1, (c) Initial plant height for Huti Green Bell in cycle 2 (C2)and (d) Initial plant height for Grande Naine in C2; Figure S3: Growth of pseudostem (L) over time in Grande Naine of individual plants in cycle 2 (C2). Dots indicate actual growing measurements, lines indicate local non-parametric regression curves of individual plants under full irrigation (FI) and Rainfed (RF). Red dots indicate the intersection of the regression 
curves with the date of flowering of $\mathrm{C} 2$ and show the interpolated VpseudoFlower; Figure S4: Components of aboveground vegetative dry biomass (ABGVD, $\mathrm{kg} \mathrm{plant}^{-1}$ ). (a) Leaf dry weight (leafD, $\mathrm{kg} \mathrm{plant}^{-1}$ ) versus pseudostem volume (L); (b) Petiole dry weight (petD, kg plant $^{-1}$ ) versus pseudostem volume (L); (c) Pseudostem dry weight (pseudostemD, $\mathrm{kg}_{\text {plant }}{ }^{-1}$ ) versus pseudostem (L). Used regression models in (a), (b) and (c) were specific models for treatment and cultivar using pseudostem volume as predictor. (d) Ratio between sum of leafD and petioleD to pseudostemD. FI notes full irrigation, RF notes rainfed. Table S1: Dry matter (DM, g dry matter $g$ fresh weight ${ }^{-1}$ ) (mean and sd) of the plant organs obtained in the field trial. Moisture contents were determined from subsamples of plant organs taken at harvest from the different cycles. Treatment differences were not significant $(p<0.05)$, leading to the pooling of data across the treatments (FI: full irrigation and RF: rainfed) per cycle (C1, C2 and C3) to obtain a dry matter percentage per organ per cycle.

Author Contributions: Conceptualization: B.S., J.D., A.B., P.A.N., R.S.; Data curation: B.S.; Formal analysis: B.S.; Funding acquisition B.S., J.D., R.S; Investigation: B.S., S.B.; Methodology: B.S., J.D., R.S.; Project administration: B.S., J.D., R.S.; Resources: B.S., J.D., A.B., P.A.N., R.S.; Software: B.S.; Supervision J.D., A.B., P.A.N., R.S.; Writing-original draft: B.S., J.D., A.B., B.S.; Writing-review and editing: B.S., J.D., R.S.; Visualization: B.S. All authors have read and agreed to the published version of the manuscript.

Funding: This research was funded by the Belgian VLIR-UOS VLADOC scholarship, grant number NDOC2016PR0009. The authors are also grateful to all donors who supported this work through their contributions to the CGIAR Fund (https://www.cgiar.org/funders/) and in particular to the CGIAR Research Program for Roots, Tubers, and Bananas (CRP-RTB).

Acknowledgments: This study was conducted at the joint research farm of the Nelson Mandela African Institution of Science and Technology (NM-AIST) and the International Institute of Tropical Agriculture (IITA), hence many people were involved. We thank the many people involved in fieldwork and technical assistance: Erick Wangaely, Salim Ramadhani, and Joshua Jackson for the maintenance of the field; Hassan Mduma and Veronica Massawe for their practical guidance and Scola Ponera and Joyce Rugakingila for administrative support.

Conflicts of Interest: The authors declare no conflict of interest.

\section{Abbreviations}

Abbreviated growth parameters are found in Table 1.

C1, C2, and C3 Cycle 1, 2, and 3

EAHB East African Highland Banana

FI Full irrigation

GN Cavendish-Grande Naine

HG Mchare-Huti Green Bell

IITA International Institute of Tropical Agriculture

NM-AIST Nelson Mandela African Institution of Science and Technology

RF Rainfed

RFH Ratio of moisture received to ET0 between flowering and harvest

RPF Ratio of moisture received to ET0 between planting and flowering

$\mathrm{RPH} \quad$ Ratio of moisture received to ET0 between planting and harvest

WLS Weighted least squares regression

\section{References}

1. FAOSTAT. Banana And Plantain Production Data. Available online: http://www.fao.org/faostat/en/\#data/ (accessed on 14 August 2020).

2. Robinson, J.C.; Galán Saúco, V. Bananas and Plantains, 2nd ed.; Longmans: London, UK, 2010; ISBN 9781845936587.

3. Swennen, R.; Langhe, E.D. Growth Parameters of Yield of Plantain (Musa cv. AAB). Ann. Bot. 1985, 197-204, 197-204. [CrossRef]

4. Mukasa, H.H.; Ocan, D.; Rubaihayo, P.R.; Blomme, G. Relationships between bunch weight and plant growth characteristics of Musa spp. assessed at farm level. MusAfrica 2005, 16, 2-3.

5. Nyombi, K.; Van Asten, P.J.A.; Leffelaar, P.A.; Corbeels, M.; Kaizzi, C.K.; Giller, K.E. Allometric growth relationships of East Africa highland bananas (Musa AAA-EAHB) cv. Kisansa and Mbwazirume. Ann. Appl. Biol. 2009, 155, 403-418. [CrossRef]

6. Niklas, K.J. Plant allometry: Is there a grand unifying theory? Biol. Rev. 2004, 79, 871-889. [CrossRef] [PubMed] 
7. Picard, N.; Saint-André, L.; Henry, M. Manual for Building Tree Volume and Biomass Allometric Equations: From Field Measurement to Prediction; Food and Agricultural Organization of the United Nations, Rome, and Centre de Coopération Internationale en Recherche Agronomique pour le Développement: Rome, Italy, 2012.

8. Negash, M.; Starr, M.; Kanninen, M. Allometric equations for biomass estimation of Enset (Ensete ventricosum) grown in indigenous agroforestry systems in the Rift Valley escarpment of southern-eastern Ethiopia. Agrofor. Syst. 2013, 571-581. [CrossRef]

9. Wairegi, L.W.I.; van Asten, P.J.A.; Tenywa, M.; Bekunda, M. Quantifying bunch weights of the East African Highland bananas (Musa spp. AAA-EA) using non-destructive field observations. Sci. Hortic. 2009, 121, 63-72. [CrossRef]

10. Yamaguchi, J.; Araki, S. Biomass production of banana plants in the indigenous farming system of the East African Highland A case study on the Kamachumu Plateau in northwest Tanzania. Agric. Ecosyst. Environ. 2004, 102, 93-111. [CrossRef]

11. Swennen, R. A Physiological Study of the Suckering Behaviour in Plantain (Musa cv. AAB). Part II Observations and Experiments. Ph.D. Thesis, KU Leuven, Leuven, Belgium, 1984; pp. 21-113.

12. Soares, J.D.R.; Pasqual, M.; Lacerda, W.S.; Silva, S.O.; Donato, S.L.R. Comparison of techniques used in the prediction of yield in banana plants. Sci. Hortic. 2014, 167, 84-90. [CrossRef]

13. Woomer, P.L.; Bekunda, M.A.; Nkalubo, S.T. Estimation of Banana Yield Based on Bunch Phenology. Afr. Crop Sci. J. 1999, 7, 341-347. [CrossRef]

14. Taulya, G. Ky'osimba Onaanya: Understanding Productivity of East African Highland Banana. Ph.D. Thesis, Wageningen University, Wageningen, The Netherlands, 2015.

15. Tixier, P.; Malézieux, E.; Dorel, M.; Wery, J. SIMBA, a model for designing sustainable banana-based cropping systems. Agric. Syst. 2008, 97, 139-150. [CrossRef]

16. Nyine, M.; Uwimana, B.; Akech, V.; Brown, A.; Ortiz, R.; Doležel, J.; Lorenzen, J.; Swennen, R. Association genetics of bunch weight and its component traits in East African highland banana (Musa spp. AAA group). Theor. Appl. Genet. 2019. [CrossRef] [PubMed]

17. Peng, B.; Guan, K.; Tang, J.; Ainsworth, E.A.; Asseng, S.; Bernacchi, C.J.; Cooper, M.; Delucia, E.H.; Elliott, J.W.; Ewert, F; et al. Towards a multiscale crop modelling framework for climate change adaptation assessment. Nat. Plants 2020, 6, 338-348. [CrossRef] [PubMed]

18. Carr, M.K.V. The water relations and irrigation requirements of banana (Musa spp.). Exp. Agric. 2009, 45, 333-371. [CrossRef]

19. Van Asten, P.J.A.; Fermont, A.M.; Taulya, G. Drought is a major yield loss factor for rainfed East African highland banana. Agric. Water Manag. 2011, 98, 541-552. [CrossRef]

20. Fortescue, J.A.; Turner, D.W.; Romero, R. Evidence that banana (Musa spp.), a tropical monocotyledon, has a facultative long-day response to photoperiod. Funct. Plant Biol. 2011, 38, 867-878. [CrossRef]

21. Holder, G.D.; Gumbs, F.A. Effects of irrigation at critical stages of ontogeny of the banana cv. "Robusta" on growth and yield. Trop. Agric. 1982, 59, 221-226.

22. Weiner, J. Allocation, plasticity and allometry in plants. Perspect. Plant Ecol. Evol. Syst. 2004, 6, $207-215$. [CrossRef]

23. Taulya, G. East African highland bananas (Musa spp. AAA-EA) "worry" more about potassium deficiency than drought stress. Field Crop. Res. 2013, 151, 45-55. [CrossRef]

24. Robinson, J.C.; Nel, D.J. Plant density studies with banana (cv. Williams) in a subtropical climate. II. Components of yield and seasonal distribution of yield. J. Hortic. Sci. 1989, 64, 211-222. [CrossRef]

25. Stevens, B.; Diels, J.; Vanuytrecht, E.; Brown, A.; Bayo, S.; Rujweka, A.; Richard, E.; Alois, P.; Swennen, R. Canopy cover evolution, diurnal patterns and leaf area index relationships in a Mchare and Cavendish banana cultivar under different soil moisture regimes. Sci. Hortic. 2020, 267, 109328. [CrossRef]

26. IUSS Working Group WRB. World Reference Base for Soil Resources 2014. International Soil Classification System for Naming Soils and Creating Legends for Soil Maps; World Soil Resources Report No. 106; FAO: Rome, Italy, 2014; ISBN 9789251083697.

27. FAO. Agro-Ecological Zoning Guidelines. FAO Soils Bulletin 73. Available online: http://www.fao.org/3/ W2962E/W2962E00.htm (accessed on 20 August 2020).

28. Robinson, J.C.; Alberts, A.J. Growth and yield Responses of Banana (Cultivar 'Williams') to drip irrigation under Drought and Normal Rainfall Conditions in the Subtropics. Sci. Hortic. 1986, 30, 187-202. [CrossRef] 
29. Varma, V.; Bebber, D.P. Climate change impacts on banana yields around the world. Nat. Clim. Chang. 2019, 1-9. [CrossRef] [PubMed]

30. Perrier, X.; Jenny, C.; Bakry, F.; Karamura, D.; Kitavi, M.; Dubois, C.; Hervouet, C.; Philippson, G.; Langhe, E. De East african diploid and triploid bananas: A genetic complex transported from south-east Asia. Ann. Bot. 2019, 123, 19-36. [CrossRef]

31. Ploetz, R.C.; Kepler, A.K.; Daniells, J.; Nelson, S.C. Banana and plantain-An overview with emphasis on Pacific island cultivars. Musaceae (banana family). Species Profiles Pac. Isl. Agrofor. 2007, 1, 7-12.

32. Meya, A.I.; Ndakidemi, P.A.; Mtei, K.M.; Swennen, R.; Merckx, R. Optimizing soil fertility management strategies to enhance banana production in volcanic soils of the Northern Highlands, Tanzania. Agronomy 2020, 289, 1-21.

33. Banana Production Manual; NARO: Kampala, Uganda, 2001.

34. Van Gaelen, H. Evaluating Agricultural Management from Field to Catchment Scale Development of a Parsimonious Agro-Hydrological Model. Ph.D. Thesis, KU Leuven, Leuven, Belgium, 2016.

35. Kallarackal, J.; Milburn, J.; Baker, D. Water Relations of the Banana. III. Effects of Controlled Water Stress on Water Potential, Transpiration, Photosynthesis and Leaf Growth. Aust. J. Plant Physiol. 1990, 17, 79. [CrossRef]

36. Thomas, D.S.; Turner, D.W. Leaf gas exchange of droughted and irrigated banana cv. Williams (Musa spp.) growing in hot, arid conditions. J. Hortic. Sci. Biotechnol. 1998, 73, 419-429. [CrossRef]

37. Taiz, L.; Zeiger, E. Plant Physiology; Sinauer: Sunderland, MA, USA, 2002; ISBN 0878938230.

38. Mahouachi, J. Growth and mineral nutrient content of developing fruit on banana plants (Musa acuminata AAA, 'Grand Nain') subjected to water stress and recovery. J. Hortic. Sci. Biotechnol. 2007, 82, 839-844. [CrossRef]

39. Turner, D.W.; Fortescue, J.A.; Thomas, D.S. Environmental physiology of the bananas (Musa spp.). Braz. J. Plant Physiol. 2007, 19, 463-484. [CrossRef]

40. Taulya, G.; van Asten, P.J.A.; Leffelaar, P.A.; Giller, K.E. Phenological development of East African highland banana involves trade-offs between physiological age and chronological age. Eur. J. Agron. 2014, 60, 41-53. [CrossRef]

41. Henry, M.; Picard, N.; Trotta, C.; Manlay, R.J.; Valentini, R.; Bernoux, M.; Saint-André, L. Estimating tree biomass of sub-Saharan African forests: A review of available allometric equations. Silva Fenn. 2011, 45, 477-569. [CrossRef]

42. Kebede, B.; Soromessa, T. Allometric equations for aboveground biomass estimation of Olea europaea L. subsp. cuspidata in Mana Angetu Forest. Ecosyst. Health Sustain. 2018, 4, 1-12. [CrossRef]

43. Eisenhauer, J.G. Regression through the Origin. Teach. Stat. 2003, 25, 76-80. [CrossRef]

44. Lassoudière, A. Le Bananier et sa Culture; Savoir Faire: Montpellier, France, 2007; ISBN 978-2-7592-0046-7.

45. Rodrigo, V.H.L.; Stirling, C.M.; Teklehaimanot, Z.; Nugawela, A. The effect of planting density on growth and development of component crops in rubber/banana intercropping systems. Field Crop. Res. 1997, 52, 95-108. [CrossRef]

46. Stover, R.H.; Simmonds, N.W. Bananas; Longman Scientific \& Technical: Harlow, UK, 1987; ISBN 0582463572.

47. Dens, K.R.; Romero, R.A.; Swennen, R.; Turner, D.W. Removal of bunch, leaves, or pseudostem alone, or in combination, influences growth and bunch weight of ratoon crops in two banana cultivars. J. Hortic. Sci. Biotechnol. 2008, 83, 113-119. [CrossRef]

(C) 2020 by the authors. Licensee MDPI, Basel, Switzerland. This article is an open access article distributed under the terms and conditions of the Creative Commons Attribution (CC BY) license (http://creativecommons.org/licenses/by/4.0/). 